\title{
EVOLUCIÓN DEL ESTADO DEL BIENESTAR DESDE UNA PERSPECTIVA DE GÉNERO. ¿GENEALOGÍA DE UNA EXPROPIACIÓN?
}

\author{
Evolution of the Welfare State from a Gender \\ Perspective. ¿A Genealogy of Expropriation?
}

Jezabel Lucas-García jezabelamparo.lucas@uva.es Universidad de Valladolid. España

Siro Bayón-Calvo

siro.bayon@uva.es

Universidad de Valladolid. España

Fecha de recepción: 03/07/2017

Fecha de aceptación: 13/09/2017

RESUMEN: La cobertura de las necesidades sociales de la población ha sido objeto de diferentes formas y grados de intervención a lo largo de la historia de los Estados modernos. Sin embargo, el Estado del Bienestar no ha generado estrategias que garanticen la equiparación en el acceso a los derechos sociales de hombres y mujeres. Cuestiones como el trabajo reproductivo, la subsidiariedad respecto al mercado de trabajo, o el desigual grado de mercantilización han tenido un papel secundario.

Este trabajo trata de analizar la genealogía del Estado del Bienestar bajo una perspectiva de género, estudiando las críticas que la teoría feminista ha planteado. Para ello, se ha realizado una aproximación histórica teniendo en cuenta las corrientes feministas que analizan la evolución de la vindicación del movimiento de mujeres dentro del ámbito de la promoción del bienestar social. Además, se presentan datos que avalan los argumentos y reflexiones propuestas.

Estos elementos permiten iniciar una reflexión sobre la posibilidad de que se haya producido un ejercicio de expropiación del bienestar social. En este sentido, aquellas personas que han contribuido a la provisión de cuidados (mayoritariamente mujeres), se han podido ver desprovistas de protección en favor de mejorar las condiciones de vida y la promoción de aquellos que lo han hecho a partir de los rendimientos del trabajo productivo.

Palabras clave: Estado del Bienestar; política social; teoría feminista; acción social. 
ABSTRACT: Coverage of population social needs has been implemented in various types throughout the history of modern states. However, welfare state has not developed strategies in order to assure the equal access to rights between men and women. Issues like reproductive work, subsidiarity from labour market, or the unequal degree of demercantilization have been subordinated to other topics.

In this article, we try to analyse the genealogy of welfare state from a gender perspective. We study the criticisms introduced by feminist theories. In order to do this, we describe an historical approximation that bear in mind the perspectives that analyses the evolution of women vindication movements within the field of social welfare promotion. Furthermore, we present data related to the feminists' approaches that endorses their arguments and discourses.

Thus, these elements allow us to explore a reflection about the concept of expropriation of welfare. In this sense, those who have contributed to the supply of social care (mainly women) may have been devoid of protection, and that would be in favour of the promotion and improvement of welfare of those who have been protected from their position in the labour market.

Keywords: Welfare state; social policy; feminist theory; social action.

SUMARIO: 1. Introducción. 2. Genealogía del Estado del Bienestar. 2.1. Las luces y las sombras de la Ilustración. 2.2. Siglo XVIII en España. 2.3. La revolución industrial. Movimiento obrero y el papel de las mujeres trabajadoras. 2.4. Siglo XIX en España. 2.5. Siglo Xx: la construcción del Estado del Bienestar. 2.5.1. Aproximación histórica al modelo de Estado del Bienestar. 2.5.2. Condiciones para el desarrollo del Estado del Bienestar y cambios estructurales que provocan su permanente "crisis». 2.5.3. Tipologías de Estado del Bienestar. 2.6. El Estado del Bienestar en España: contexto, origen y periodos fundamentales. 3. Críticas a la evolución del Estado del Bienestar desde una perspectiva de género. 3.1. Madres, empleadas y ciudadanas invisibilizadas. 3.2. El sesgo de la ciudadanía marshalliana. 3.3. Desmercantilización y empleo femenino. 4. El Estado del Bienestar bajo un enfoque feminista. 4.1. Políticas dirigidas a mujeres versus políticas de igualdad de género. 4.2. La mercantilización libertadora. 4.3. Dependencia/Independencia intrafamiliar. 4.4. Trabajo remunerado y no remunerado en relación con el bienestar. Nueva tipología del Estado del Bienestar. 4.5. El modelo male breadwinner versus el modelo individual. 4.6. Los cuidados o social care. La introducción de la función de cuidados en las tipologías de Estados del Bienestar. 5. Consideraciones finales: ¿Hablamos de expropiación del bienestar? 6. Referencias bibliográficas.

\section{INTRODUCCIÓN}

A lo largo de los siglos han sido diversas las estrategias que las sociedades han empleado para atender las necesidades básicas de las personas más vulnerables. En Occidente, la política social tras la Segunda Guerra Mundial se ha basado en el desarrollo del Estado del Bienestar. Para estudiar su configuración desde un enfoque de género, en este trabajo se analiza el periodo comprendido desde el siglo XVIII hasta nuestros días. Esta elección se debe a dos razones: a partir de este momento se producen una serie de acontecimientos que generan la emergencia de los Estados-nación modernos como fórmula específica de organización de la política estatal. Además, este periodo se corresponde con la genealogía del 
feminismo; hay autoras ${ }^{1}$ que convienen en afirmar que el concepto de feminismo, entendido como teoría crítica y como movimiento social, comienza en el periodo Ilustrado "El feminismo es, en principio, una conquista ilustrada» (Molina Petit, 1994, p. 20).

Los hitos y personajes históricos destacados en esta genealogía no conforman un relato cronológico detallado de los acontecimientos más relevantes de estos siglos, sino que se analizan con el objetivo de visibilizar aquellos hechos que mejor pueden argumentar la reflexión que forma parte de la hipótesis de partida, la de considerar que los Estados-nación emergentes en el mundo moderno occidental han configurado unos modelos de protección social sin tener en cuenta la desigual participación en la esfera productiva y reproductiva de hombres y mujeres. Son modelos que, en mayor o menor grado, han evolucionado de manera subsidiaria del mercado laboral y, por tanto, han privilegiado la protección de las personas que participaban en él, desprotegiendo a aquellas que han provisto de bienestar social a la población en la esfera familiar (mayoritariamente mujeres).

El presente trabajo analiza el desarrollo histórico de los Estados del Bienestar desde una perspectiva de género, estudiando la aportación de las críticas de la teoría feminista y explorando los nuevos enfoques que se proponen.

En cuanto a la estructura del trabajo, tras la introducción, en el segundo epígrafe se realiza un esbozo de la genealogía del Estado del Bienestar en el entorno europeo y el contexto específico de España, prestando especial atención al tratamiento de la protección social y la posible (des)atención hacia las mujeres.

El tercer epígrafe consiste en recoger las críticas realizadas desde la teoría feminista, centrándonos de manera específica en las vertidas sobre la tipología de Estado del Bienestar planteada por Esping-Andersen (1990). Para ello, se presentan datos que apoyan los discursos y reflexiones de estas teorías y que invitan a reflexionar sobre conceptos como la invisibilización de las mujeres, la desmercantilización femenina o la ciudadanía marshalliana.

El cuarto epígrafe, se encarga de presentar los principales debates y propuestas relativas a los modelos de Estados del Bienestar bajo un enfoque de género.

El quinto epígrafe trata de integrar las conclusiones de este trabajo, y plantea el concepto de expropiación del bienestar como característica estructural que ha vertebrado la genealogía del Estado del Bienestar.

${ }^{1}$ Algunas referencias bibliográficas que mantienen esa premisa ilustradora son Amorós y de Miguel, 2007; Amorós y Cobo, 2007; Caine y Sluga, 2000; Puleo, 1993; Molina Petit, 1994; y Valcárcel, 1991. 


\section{GENEALOGÍA DEL ESTADO DEL BIENESTAR}

El carácter de la hipótesis planteada en este trabajo obliga a reconducir el recorrido histórico, poniendo de relieve el concepto de ciudadanía e igualdad que surge tras la ilustración en el siglo XVIII, el desarrollo de la industrialización y el movimiento obrero en el siglo XIX y, en último término, el advenimiento de los derechos sociales con el origen del Estado del Bienestar, situado entre finales del siglo XIX y mediados del siglo XX. Todo ello incorporando las principales vindicaciones feministas surgidas en las distintas épocas y teniendo en cuenta los avances históricos en materia de asistencia social pública que se desarrollan en el contexto español.

\subsection{Las luces y las sombras de la llustración}

Como señala Thiebaut (1991), a partir de la llustración nacen «unos ideales éticos que impulsaron el progreso de la historia occidental, pero que fueron incapaces de evitar los hitos amargos de esa misma historia». Con estas líneas se hace presente la limitación de acceso de las mujeres a estos ideales y, por tanto, su condición de ciudadanas: igualdad, propiedad, razón, progreso o educación, entre otros, son valores que gracias a la Revolución Francesa convierten al súbdito en ciudadano. $Y$ decimos ciudadano y no ciudadana porque las mujeres se van a quedar al margen (Amorós y de Miguel, 2007; Amorós y Cobo, 2007; Caine y Sluga, 2000; Duhet, 1989; Puleo, 1993; Molina Petit, 1994; Sánchez Muñoz, 2001; Scott 1993; Valcárcel, 1991, 2008).

Uno de los acontecimientos históricos que definen esta época es la Revolución Francesa y con ella la promulgación el 26 de agosto de 1789 de la Declaración de los Derechos del Hombre y del Ciudadano, en la que se promocionan valores de libertad, propiedad, resistencia a la opresión, igualdad o justicia. Todos ellos promueven medidas de atención a las necesidades sociales de la población desde una concepción de responsabilidad política (Gallego Ayllón y González Vélez, 1997).

Los Estados modernos comienzan paulatinamente a asumir competencias sociales en detrimento del protagonismo que hasta el momento ejerce la Iglesia. De hecho, la Declaración del Hombre y del Ciudadano de 1793 aprueba que "La sociedad debe asegurar la subsistencia de los ciudadanos desprotegidos, ya sea procurándoles un trabajo, ya sea asegurando los medios de existencia a los que no estén en condiciones de trabajar» (Montagut, 2000, p. 52).

Se dispusieron también normas que mejoraron las condiciones sociales de las mujeres: se fija una mayoría de edad igual (veintiún años), se deroga el derecho de primogenitura masculina, y se admite el divorcio en condiciones de igualdad (Sánchez Muñoz, 2001). Los ideales políticos ilustrados nacen bajo un principio universalista, pero las sombras comienzan: en la Declaración de los Derechos del 
Hombre y del Ciudadano se articulan los principios de igualdad, razón, libertad o propiedad para los hombres a partir de su nacimiento. Van a ser los hombres los que definan el contrato social. El hecho de que los derechos sean ejercidos por varones, blancos, burgueses y propietarios de una comunidad política, supuso "la chispa que hizo nacer el pensamiento feminista tal y como hoy lo conocemos y con los mismos rasgos que tiene y conserva en la actualidad» (Valcárcel, 2008, p. 59). En este contexto y frente a estas vindicaciones, se pueden situar dos figuras relevantes: Mary Wollstonecraft y Olympe de Gouges.

Mary Wollstonecraft escribe en 1792 su Vindicación de los Derechos de la Mujer. Con esta obra contra-argumenta el análisis de Rousseau desde una lógica universalista: si los hombres nacen libres e iguales como proclama el Artículo I de la Declaración de los Derechos del Hombre y del Ciudadano, ¿por qué no mantener el mismo discurso ampliándolo a toda la población? Como apunta Cobo (1995), sus observaciones se ven rápidamente desplazadas por la producción teórica rousseauniana, ya que el filósofo mantiene que en los orígenes del ser humano sí existe un estado de naturaleza sin diferenciación, pero, más tarde, la sociedad se organiza y es a partir de la familia cuando surge la desigualdad, y por ende, la jerarquía.

Olympe de Gouges redacta en 1791 la Declaración de los derechos de la mujer y de la ciudadana. La estrategia de la autora radica en adoptar la misma estructura de la Declaración de los derechos del Hombre y del Ciudadano, pero introduciendo a las mujeres en estos derechos de ciudadanía. Ello supone un ejercicio de integración que denuncia la falsa universalidad de la corriente ilustrada más influyente (Duhet, 1989; Sánchez Muñoz, 2001)

\subsection{Siglo xVIII en España}

El siglo XVIII en España, desde el punto de vista de la intervención estatal sobre las necesidades sociales de la población, está caracterizado por una serie de rasgos principales (Gallego Ayllón y González Vélez, 1997; Alemán Bracho y Trinidad Requena, 2006; Alemán Bracho, Alonso Seco y Fernández Santiago, 2010).

En primer lugar, comienza un periodo de reformas y modernización del país donde se destaca el desarrollo de políticas activas en materia de obras públicas, una reorganización administrativa que promociona el fomento y la colonización de territorios desocupados, se promocionan sectores como el comercio y la artesanía, y se impulsan las artes, letras y ciencias. A partir de este periodo se fomenta la educación y la publicación de periódicos. Tanto la cultura como la educación van a ser profundamente avaladas por la modernización española, al entender su promoción como condiciones previas de acceso a la felicidad y prosperidad social.

En segundo lugar, se produce un desplazamiento del poder eclesiástico en materia de asistencia social, con un claro objetivo laicista. En España, al igual que 
en otros Estados, los poderes públicos empiezan a ejercer el control sobre aspectos de la vida pública como la previsión social, la economía o la asistencia. De hecho, el pensamiento ilustrado critica la defensa a ultranza de la caridad que realiza la Iglesia porque estas ayudas alientan únicamente a sus benefactores a continuar pidiendo en lugar de buscar trabajo, de ahí la necesidad de crear una asistencia pública que trate de emplear a personas, rechazando todo tipo de acción caritativa y persiguiendo a aquellos que la solicitasen ${ }^{2}$ "los ilustrados rechazan la práctica de la limosna, por considerar que fomenta la pobreza y ociosidad y los vicios anexos a ella» (Alemán Bracho, et al., 2010, p. 85).

Cabe señalar también el cambio de mentalidad respecto a la pobreza, ya que empieza a entenderse el fenómeno de la pobreza como un ámbito en el que es necesario intervenir y así evitar resistencias al régimen. Se mantiene un especial interés en convertir a las personas pobres en productivas y no únicamente personas al amparo de la beneficencia pública. Por esta razón, se perseguirá a las personas vagabundas con la finalidad de obligarles a trabajar.

Otro aspecto destacable es la aparición de las Sociedades económicas de amigos del país. En ellas se insta a la movilización de la comunidad, bajo la noción de que no es posible la modernización del país tan solo a partir de la acción de sus dirigentes. En estas sociedades, nobles, intelectuales, y clérigos a favor de las reformas se reunían con el ánimo de analizar los recursos y características de las regiones y proponer cambios e innovaciones.

Las reformas eran necesarias porque el contexto social así lo requiere. La mayor parte de la población de la época vive en condiciones de miseria y pobreza, en marzo de 1766, una masa importante de personas se moviliza contra las nuevas directrices de uno de los principales ministros del Rey Carlos III, el Marqués de Esquilache, al que se responsabiliza de la hambruna que asola el país por las reformas económicas que el éste promueve.

Por otro lado, las acciones legislativas promulgadas por Carlos III y Carlos IV se ponen en marcha con el objetivo de obtener un mayor control y administración de los territorios, luchar contra la pobreza, la creación de alojamientos para los considerados «verdaderos pobres», entre otros.

En último lugar, se pueden destacar varias acciones administrativas. A modo de control social se crea el Real Hospicio de San Fernando, suerte de cárcel, pero con un trato menos represor. Otra acción administrativa relevante es la creación de las denominadas Diputaciones de Barrio, donde se realizan diferentes actividades de carácter social. Apostar por la educación femenina es una decisión pionera en

2 Aunque estos argumentos ilustrados datan de hace tres siglos, actualmente continúan enraizados en nuestra cultura. Existen en nuestro contexto discursos que critican el sistema de prestaciones y ayudas sociales por considerar que promocionan la cronicidad y la dependencia de las personas que acceden a ellas. 
la época. A pesar de las iniciativas sociales que aquí se llevan a cabo, se mantiene un carácter represor al tener como principal objetivo el control sobre la población pobre. Por último, los Montepíos se consideran un avance de lo que ahora entendemos por seguros sociales. Su finalidad es asegurar riesgos laborales como la enfermedad, los accidentes, la incapacidad o la muerte.

\subsection{La revolución industrial. Movimiento obrero y el papel de las mujeres trabajadoras}

El paso entre el siglo XVIII y el siglo XIX es un periodo de cambios "orientados hacia la paulatina trasformación de los problemas sociales en cuestiones de naturaleza pública y responsabilidad política» (Alemán Bracho, et al., 2010, p. 109).

Con la llegada de la Revolución Industrial se socializa el capitalismo, trasladándose a todos los ámbitos de la vida económica, política, social y cultural de los Estados modernos ${ }^{3}$.

El cambio de propiedad de las tierras comunales a manos privadas a partir del siglo XVIII (Gallego Ayllón y González Vélez, 1997) genera un traslado masivo de campesinos/as a las ciudades con la finalidad de ofrecerse como mano de obra ante el nuevo sistema industrial emergente. En las fábricas, bajo unas míseras e insalubres condiciones, hombres, mujeres y niños/as trabajan durante largas jornadas laborales a cambio de salarios por debajo de los niveles de vida aceptables y sin ningún tipo de cobertura en caso de riesgo laboral.

El hacinamiento de la población, la insalubridad, las malas condiciones de las viviendas, no sólo hacían insostenible la situación. Le otorgaban una trascendencia y una gravedad desconocida hasta entonces. Por más que nunca haya existido la pobreza como mera cuestión individual, su nuevo planteamiento insertaba al problema ya en una órbita decididamente colectiva y social. (Alemán Bracho, et al., 2010, p. 110).

A lo largo del siglo XIX, son varios los intentos de reforma legislativa a favor de mejorar las condiciones laborales de niños y niñas. En la Ley de Sanidad y Salubridad de 1802 se mejoran las condiciones de la mano de obra infantil, se reduce su jornada laboral y se prohíbe el trabajo nocturno (Gallego Ayllón y González Vélez, 1997). No obstante, esta ley tan solo afecta a los niños/as de los hospicios, por lo que, los empresarios contratan directamente a niños/as de familias pobres y les explotan sin miramientos. Como señalan Alemán Bracho et

3 Autores como Alemán Bracho y Trinidad Requena (2006), Alemán Bracho et al. (2010), Artola Gallego y Pérez Ledesma (1990), Gallego Ayllón y González Vélez (1997), Giddens (2009) o Montagut (2000) nos ofrecen una noción general de sus principales características. 
al. (2010), una ley posterior, denominada Ley de Fábricas, prohíbe la contratación de niños/as menores de 9 años. Todas las iniciativas sociales llevadas a cabo en este siglo no solo tienen el objetivo de minimizar los estragos que el capitalismo genera en la población, sino también el de controlar el levantamiento del proletariado.

Las condiciones laborales de los/as trabajadores/as industriales se convierten en el punto de partida de la creación de la conciencia de clase obrera que genera un movimiento de lucha para intentar mejorar sus condiciones. Son los inicios del movimiento sindical (Artola Gallego y Pérez Ledesma, 1990). Este hecho junto con la aparición de los partidos políticos de masas, va a protagonizar los acontecimientos de este siglo.

Gracias a la lucha obrera paulatinamente, en un proceso duro y plagado de conflictos, se van a ir consiguiendo diferentes logros de carácter social:

Reconocimiento de las asociaciones y sindicatos obreros, admisión del derecho a huelga, regulación del trabajo de mujeres, niños y hombres, reducción de la jornada de trabajo, establecimiento de escalas de salarios, adecuación higiénica de fábricas y talleres, viviendas obreras, seguros obligatorios para la enfermedad, accidentes de trabajo e invalidez. (Gallego Ayllón y González Vélez, 1997, p. 46).

Los éxitos sociales alcanzados dan cuenta del cambio de mentalidad existente con respecto al siglo anterior, un cambio que permite considerar a las personas como ciudadanas de un Estado y, por tanto, susceptibles de recibir su protección. La intervención pública surge para atajar los efectos que la industrialización genera en la recién estrenada ciudadanía. Pero, ¿van las mujeres a formar parte de este proceso integrador?

La historiadora Joan W. Scott (1993) analiza la lógica de la división sexual del trabajo que se genera a partir de la industrialización y considera que esta forma parte de un proceso de construcción discursiva para contraponer las esferas pública y privada, la domesticidad frente a la productividad y, debido a ello, la oposición entre mujeres y empleo, producción y reproducción: «en el siglo XIX se le observa [a la mujer], se le describe y se le documenta con una atención sin precedentes, mientras los contemporáneos discuten la conveniencia, la moralidad e incluso la licitud de sus actividades asalariadas. La mujer trabajadora fue un producto de la revolución industrial» (Scott, 1993, p. 405).

La lógica de la separación de esferas y tareas basadas en la condición sexual de la ciudadanía fundamenta las bases del desarrollo económico industrial capitalista. Este sistema se entiende como una forma de organizar la sociedad de manera más eficiente, racional y productiva. Un sistema bajo el que se asienta la génesis del Estado del Bienestar. 
Para Scott (1993), ha habido un claro ejercicio de invisibilización del empleo productivo y asalariado de las mujeres en épocas preindustriales; según Nash (1993), en los siglos XVII y XVIII las mujeres ya trabajaban fuera de sus hogares. y eran decisivas para la supervivencia económica de sus familias. Sin embargo, históricamente se presenta la imagen de un mundo preindustrial donde la mano de obra es familiar y la economía se circunscribe al ámbito doméstico.

en el periodo previo a la industrialización las mujeres ya trabajaban fuera de sus casas. Casadas y solteras vendían bienes en los mercados, se ganaban su dinero como pequeñas comerciantes y buhoneras, se empleaban fuera de casa como trabajadoras eventuales, niñeras o lavanderas y trabajaban en talleres de alfarería, de seda, de encaje, de confección de ropa, de productos de metal, quincallería paño tejido o percal estampado. Si el trabajo entraba en conflicto con el cuidado de los hijos, las madres, antes que dejar el empleo, preferían enviar a sus críos a nodrizas u otras personas que se hicieran cargo de ellos. (Scott, 1993, p. 409).

En el siglo XIX, a partir de la industrialización, se van a crear nuevos puestos de trabajo de carácter industrial donde también participan las mujeres, preferentemente en la industria textil o en empleos de cuello blanco (enfermeras, maestras, secretarías, etc.). Estos empleos se ofertan mayoritariamente a mujeres de clases medias. A estas ocupaciones se les añaden aquellas actividades tradicionalmente asignadas a las mujeres: niñeras, criadas, lavanderas, entre otras.

Estos hechos generan los debates en torno a la conveniencia de la existencia de mujeres asalariadas: «¿debe una mujer trabajar por una remuneración?, ¿cómo influía el trabajo salariado en el cuerpo de la mujer y en la capacidad de ésta para cumplir funciones maternales y familiares?, ¿qué clase de trabajo era idóneo para una mujer?» (Scott, 1993, p. 405). La economía política, los empleadores, los sindicatos y los legisladores llegan a la conclusión de que la mejor opción es la consolidación de la separación de esferas y, por tanto, la conservación de la división sexual del trabajo. Se basan en los siguientes discursos:

- La economía política apuesta por el salario familiar masculino.

El economista político francés Jean-Baptiste Say, por ejemplo, afirmaba que los salarios de las mujeres caerían siempre por debajo del nivel de la subsistencia, debido a la disponibilidad de mujeres que podían apoyarse en el sostén familiar (...) y, por tanto, no necesitaban vivir de sus salarios. En consecuencia, las mujeres solas que vivían lejos de contextos familiares y aquellas que eran el único sostén de sus familias, serían irremediablemente pobres. (Scott, 1993, pp. 416-417). 
- Las prácticas de los empleadores reafirman la división sexual del trabajo creando «trabajos de mujeres", que en muchas ocasiones se caracterizan por tener peores condiciones laborales que los que tienen los hombres. Se reafirman en considerar que las mujeres son menos productivas y que solo están capacitadas para desempeñar empleos de escasa cualificación o de servicios.

- Los sindicatos claudican ante la "supuesta» presencia amenazante de las mujeres. Creen conveniente "aplazar» las reivindicaciones de las mujeres y centrarse en proteger los empleos masculinos. Incluso en la clase obrera permean discursos burgueses y la «cultura de la domesticidad». Se elogia a mujeres que deciden permanecer en sus hogares para ser amas de casa frente a las que deseen emplearse fuera de ella:

Las mujeres podían llegar a ser "socialmente asexuadas» si realizaban trabajos de hombre y podían castrar a sus maridos si pasaban demasiado tiempo ganando dinero fuera de casa. (Scott, 1993, p. 425).

- Los Estados comienzan a redactar leyes con la finalidad de proteger a la población vulnerable, entre las que entienden a los niños/as y a las mujeres. Desde la normatividad se asume que las mujeres son vulnerables $y$, por tanto, susceptibles de recibir protección en el momento en que no se consideran ciudadanas, están alejadas del poder político y son dependientes.

El trabajo "pervertía» los órganos reproductores y afectaba la capacidad de las mujeres para procrear y criar hijos saludables; el empleo las distraía de sus quehaceres domésticos; los empleos nocturnos las exponían al peligro sexual en el taller, así como en el camino hacia y desde el lugar del trabajo; trabajar junto con hombres o bajo supervisión masculina entrañaba la posibilidad de corrupción moral. (Scott, 1993, p. 429).

\subsection{Siglo xıx en España}

La característica fundamental que podríamos elegir para identificar este periodo dentro del Estado español se resume en la palabra retraso. Todos los rasgos de los que hemos hablado anteriormente se van a producir de forma más lenta, e incluso determinadas cuestiones no llegan a plantearse. Este retraso será más acusado en el siglo Xx (en gran parte como consecuencia de la dictadura franquista). En este siglo, es donde los/as expertos/as sitúan el nacimiento del Estado del Bienestar, que en España tiene un desarrollo incompleto. Alemán Bracho et al. (2010) argumentan 
que las razones de este atraso respecto a los demás países europeos pueden explicarse por la importancia de la Iglesia en la esfera sociopolítica española, que hace que la separación Iglesia-Estado que sí establecieron otros Estados europeos no se produzca de igual manera. A esto hay que sumarle una revolución industrial no tan profunda como la existente en el resto de Europa. Aunque regiones como Cataluña o País Vasco sí consiguen este nivel de modernización, la mayor parte de la población continúa dedicándose a la agricultura dentro de un entorno rural. Por otro lado, el movimiento obrero es insuficiente en reivindicaciones y genera menores logros sociales.

Pese a estos inconvenientes, podemos ver que el Estado va avanzando progresivamente en el ámbito de la intervención pública ante los problemas sociales que surgen en la sociedad de la época. Una muestra de este avance (Alemán Bracho, et al., 2010) se puede observar en la Constitución de 1812, en la que se determina que el Estado asuma algunas actividades de asistencia social y beneficencia.

Otro acontecimiento que da cuenta del paulatino desarrollo de la protección social en España es la aparición de las Leyes de Beneficencia de 1822 y de 1849. La primera ley incluso cuenta con una serie de presupuestos públicos con los que hacer frente a las necesidades sociales de la población (Alemán Bracho, et al., 2010), se crean hospitales públicos y se construyen casas de socorro y casas de maternidad (Arrazola García, 1832). Con la segunda ley de beneficencia de 1849 se refuerza el carácter público como competencia del Estado, pero, mientras que la ley anterior posee cierto carácter descentralizador, la segunda disminuye esta capacidad, devolviendo el papel protagonista a la administración central y a las provincias (Alemán Bracho, et al., 2010).

Durante la Restauración borbónica se muestra un especial interés en intervenir sobre el avance de la pobreza que afecta a las condiciones de vida de los/as trabajadores/as fabriles: insalubridad, jornadas laborales interminables, salarios insuficientes, etc. (Alemán Bracho, et al., 2010). Los obreros se movilizan para denunciar esta situación y, en este contexto, nace en 1883 la Comisión de Reformas Sociales, cuyas funciones están comprendidas dentro las cuestiones sociales que surgen en materia de bienestar social de los trabajadores tanto agrícolas como industriales.

\subsection{Siglo xx: la construcción del Estado del Bienestar}

Existe un consenso mayoritario en situar los orígenes del Estado del Bienestar entre finales del siglo XIX y principios del siglo XX.

La génesis del Estado del Bienestar se relaciona a sus capacidades de procura social. Históricamente, los poderes públicos estatales fueron asumiendo funciones tradicionalmente desempeñadas por los concejos municipales o las 
iglesias. Tal era la situación previa a la promulgación a partir de 1834 de la New Poor Law en el Reino Unido. Para algunos historiadores dicha fecha marcó los inicios de la construcción de los sistemas contemporáneos del bienestar. (Moreno, 2000, p. 21).

Montagut (2000) sitúa más tarde los orígenes del Estado del Bienestar, en el periodo comprendido entre la primera y la segunda guerra mundial, considerando dos antecedentes fundamentales: el Estado social que se origina bajo la República de Weimar y el Informe Beveridge. En Alemania, a partir de la República de Weimar (1918-1933) se van a reconocer una serie de derechos sociales, y el Estado va a mantener un cierto carácter intervencionista en la economía. El informe Beveridge de 1942 es considerado un hito histórico con el que coinciden otros teóricos/as como Moreno (2000) o Martínez Herrero (2007).

Esping-Andersen (1993 y 2000) añade el hecho de que los primeros pasos dados hacia la construcción del Estado del Bienestar fueron medidas que llevaron a cabo la clase conservadora y liberal burguesa orientadas en oposición al movimiento obrero y al socialismo "el "Estado del Bienestar" (welfare state) fue un esfuerzo del gobierno británico, durante la segunda guerra mundial, para movilizar a sus ciudadanos en la lucha contra el "Estado de guerra" (warfare state) nazi» (EspingAndersen, 2000, p. 11).

En este epígrafe se presenta una aproximación histórica al modelo de Estado del Bienestar, se discuten las condiciones que permitieron su desarrollo, además de los cambios estructurales que provocan su permanente crisis y, por último, se establecen las tipologías más importantes de Estados del Bienestar. La finalidad de este acercamiento histórico es discutir la construcción del Estado del Bienestar erigido al amparo del trabajo de cuidados y labores del hogar que realizan fundamentalmente las mujeres y del trabajo productivo que protagonizan mayormente los hombres, luego, advertir la división sexual del trabajo existente en el sistema de provisión del bienestar. Esta lógica puede generar una expropiación de bienestar de las mujeres, porque les dificulta el acceso a los derechos de ciudadanía, especialmente el acceso a los derechos sociales.

\subsubsection{Aproximación histórica al modelo de Estado del Bienestar}

Existen una serie hitos históricos ${ }^{4}$ que dan cuenta de cómo se van configurando en Europa los modelos de protección social que prevalecen en la actualidad.

${ }^{4}$ Todos los hitos históricos aquí contemplados no son compartidos por todos los autores referenciados, pero sí la mayoría de ellos: Martínez Herrero (2007), Moreno (2000), Montagut (2000) o Polanyi (1989). 
El primero de ellos es la Derogación de las Leyes de Socorros frente al nacimiento de la New Poor Law: La Nueva Ley de Pobres promulgada en 1834 es concebida como una ley redactada para poner fin a las «leyes de socorros» o Ley Speenhamland.

un hombre podía recibir socorros, incluso cuando poseía un empleo, siempre y cuando su salario fuese inferior a la renta familiar establecida de acuerdo con un baremo. Por esto, ningún trabajador tenía interés en satisfacer a su patrono, ya que, su renta era la misma independientemente del salario acordado. (Polanyi, 1989, p. 138).

La economía de mercado moderna gana la batalla en el momento en que no es posible compaginar este procedimiento de ayudas con el sistema salarial, se entiende que la ley Speenhamland solo consigue promocionar y cronificar la pobreza (Polanyi, 1989). Según Moreno (2000), el nacimiento de la New Poor Law supone un gran avance en las medidas de intervención frente a los problemas sociales. A partir de la Nueva Ley de Pobres, el imperio británico interviene en la protección de los trabajadores pobres con medidas que intentan paliar la explotación capitalista sin que se resientan por ello los principios de la economía de mercado.

Un segundo hito lo marca la legislación social bismarckiana. En la Alemania de 1883 emergen los principios de la seguridad social actual (Moreno, 2000). Estos principios normativos suponen una protección de los trabajadores alemanes ante las posibles incidencias que pueden ocasionarles el ejercicio de su trabajo diario, lo que se traduce en una mejora de su calidad de vida. A partir de sus contribuciones periódicas, los trabajadores reciben apoyo en situaciones de enfermedad, vejez o viudedad (Montagut, 2000). Unos principios solidarios establecidos entre los empresarios, los trabajadores y el Estado, siendo esta una iniciativa propuesta por Bismarck en un intento de contrarrestar el movimiento proletario socialista (Martínez Herrero, 2007). El modelo alemán de seguros sociales se extiende durante esta época a otros países europeos como Noruega, Suecia o Austria.

En tercer lugar, podemos destacar la emergencia del modelo socialdemócrata sueco, que se conforma a finales del siglo xIX y principios del xx. La alianza política entre los nuevos trabajadores industriales y los agricultores genera un conjunto de presiones que motivan la configuración del Estado del Bienestar nórdico (Martínez Herrero, 2007). Como señala Montagut (2000), tanto los trabajadores como la patronal sueca entienden que el Estado debe intervenir y regular ciertas actividades económicas. Se crean prestaciones destinadas a incidencias que puedan producirse a lo largo de la vida laboral. Los subsidios familiares se extienden a un mayor número de población manteniendo el carácter redistributivo y universal actual.

La política intervencionista estadounidense denominada New Deal constituye el cuarto hito. Aunque choca frontalmente con la ideología individualista y 
capitalista de los Estados Unidos, la situación de enorme pobreza emergente tras las crisis de los años veinte hacen más que plausible que Roosevelt, a principios de los años treinta, considere la asunción de «ciertas responsabilidades en el ámbito económico y de la seguridad social (Martínez Herrero, 2007, p. 58). A esta nueva etapa se le unen programas sociales no tan "comprensivos" y que, junto a la ausencia de un sistema público de salud, forjan un modelo de protección social de «mínimos» (Moreno, 2000).

En quinto lugar, encontramos la lógica keynesiana. Si hubiese que buscar una obra con la que justificar teóricamente la intervención pública sobre la economía, esta sería la Teoría general del interés, la ocupación y el dinero publicada en 1936 (Keynes, 2006). En ella, Keynes trata de dar una respuesta económica a la gran depresión producida como consecuencia de la acción del capitalismo (Montagut, 2000). Frente a la teoría clásica económica imperante en la época, plantea la necesidad de que sean los Estados los que intervengan en la economía a partir de la generación de políticas sociales que eleven la renta de la población. La intención de esta intervención es doble: por un lado, si la población de un determinado territorio tiene rentas más altas, podrá destinar más dinero al consumo, logrando así garantizar el crecimiento económico; por otro lado, la creación de políticas sociales supone un mínimo de protección social para la población, eliminando así situaciones de extrema pobreza.

Montagut (2000) señala cuatro rasgos principales de los modelos de Estados del Bienestar en los que se manifiesta la lógica keynesiana. El primer rasgo es el Pacto social firmado por la ciudadanía, los empresarios y el Estado. Un consenso en el que se ratifica la intervención del Estado en temas económicos y sociales sufragados vía impuestos. El segundo rasgo es el Modelo de economía mixta, ya que el Estado no solo interviene en la economía para crear sistemas de protección social, sino que también invierte en ella a través del gasto público, creando empresas públicas que, a su vez, generen empleo público en un intento de mejorar el crecimiento económico. La universalización de la protección social sería el tercer rasgo, aquí el Estado se compromete a proveer de determinados servicios encaminados a promocionar el bienestar social. Por último, destaca la noción de Ciudadanía plena: la ciudadanía (hombres y mujeres) accede al reconocimiento formal de sus derechos civiles, políticos, y sociales.

El sexto y último hito que aquí se subraya es el informe Beveridge. La importancia fundamental de este informe, publicado en Reino Unido en 1942, radica en criticar tanto la asistencia como los seguros sociales. Se formula con el intento de extender la protección a toda la población y no solamente a los trabajadores o a las personas consideradas pobres (Martínez Herrero, 2007). Lord Beveridge (1989) entiende el sistema de la Seguridad Social como un instrumento global para terminar con cinco grandes males: la indigencia física, la enfermedad, la ignorancia, la miseria y hacinamiento, y la ociosidad. 
El informe defiende la centralización de las competencias en materia de protección social y "considera necesaria la creación de un sistema nacional de salud gratuito y abierto a toda la población» (Martínez Herrero, 2007, p. 56). Un sistema que se financiaría vía impositiva por empresarios y la propia ciudadanía. El Estado asumiría la sexta parte de las prestaciones, gran parte del gasto sanitario y la totalidad de los subsidios familiares. El informe Beveridge "proclamó el principio de cobertura universal de la seguridad social para todos los ciudadanos "desde la cuna hasta la tumba" (from cradle to grave), y con cargo a los presupuestos generales estatales financiados por todos los contribuyentes» (Moreno, 2000, p. 23).

\subsubsection{Condiciones para el desarrollo del Estado del Bienestar y cambios estructurales que provocan su permanente «crisis»}

Las principales condiciones que generan el establecimiento del Estado del Bienestar son fundamentalmente económicas. La crisis económica de 1929 y la segunda guerra mundial crean tras su paso una fuerte regulación de la economía en un intento de paliar los fallos que ha generado el mercado. Surge el denominado Pacto Keynesiano, que supone la intervención sobre la economía a partir de la suma entre el capitalismo fordista y las democracias parlamentarias surgidas de los Estados-nación de la posguerra. Tras las grandes guerras el modelo de producción imperante es el modelo de producción de consumo fordista (Alonso, 1999). Un modelo de producción que, a partir de la rutinización y la participación en la cadena de máquina-herramienta especializada, permite que se aceleren los procesos de producción. La consecuencia de esta implantación es el incremento de la productividad destinada al consumo de masas. Las condiciones de producción propuestas permean al resto de la sociedad, generándose infraestructuras y bienes públicos que lo apoyan.

En la etapa de consolidación del Estado del Bienestar no se va a cuestionar la racionalidad del capitalismo, «el Estado del Bienestar y en la misma línea "el Estado productor" no rompieron en ningún momento la racionalidad básica del sistema de mercado, pero sí la modificaron en parte con innegable éxito social desde la salida de la guerra hasta prácticamente mediados de los sesenta» (Alonso, 1999, p. 106). El objetivo en estos momentos es regular los efectos macroeconómicos, ampliar los bienes públicos, internalizar bienes privados y crear derechos sociales. Todo ello al reconocer que el mercado tiene fallos y que, por tanto, es necesaria la regulación.

Otras condiciones que van a componer la construcción del Estado del Bienestar son las condiciones político-territoriales. La historia demuestra que el marco en el que se configura el modelo es a partir del Estado-nación. El capitalismo lo regulan los diferentes Estados dentro de sus fronteras, luego los ciudadanos van a beneficiarse de ellos (en un principio sólo ciudadanos, no ciudadanas). 
Por último, cabe destacar las condiciones culturales de la construcción del Estado del Bienestar. La complementariedad que genera el capitalismo fordista y las democracias parlamentarias crean unos modos de vida concretos donde los tiempos se regulan a partir del modo de producción, distribuyendo la jornada en las famosas 8-8-8; ocho horas para el descanso, ocho horas para el trabajo, y ocho horas para el ocio. Esta distribución horaria se extiende a toda la población, aunque el modelo del diseño sea el ciudadano-trabajador industrial.

Junto a la socialización de los horarios industriales se encuentra la familia nuclear, otra de las bases culturales en las que se asienta el Estado del Bienestar, ya que en ella se plantea una clara diferenciación entre la esfera pública y la esfera privada. La esfera pública está representada por el ciudadano hombretrabajador-proveedor. Frente a este, se sitúa la esfera privada, el contexto familiar, representado por la mujer-dependiente-ama de casa y los hijos/as. Es en este espacio en el que las mujeres desempeñan el trabajo reproductivo (tareas del hogar y cuidados). En este ámbito, la ciudadanía es indirecta y vicaria, lo que significa que las mujeres y los niños/as tienen derechos en la medida en que los tenga el pater familias (Sainsbury, 1994; Montagut, 1996; Carrasco, 1997; Bottomore, 1998).

Las corrientes feministas que se tratan en el tercer epígrafe de este trabajo critican la excesiva dependencia de las familias en la provisión del bienestar, al considerar que es contraproducente para la necesaria independencia del individuo y negativa en cuanto a la carga de trabajo que supone para las mujeres.

En cuanto a los cambios estructurales que condicionan la permanente crisis del Estado del Bienestar, podemos establecer su origen en los años 60 y 70 . En estas fechas el Estado «no responde ni a las necesidades de la población ni a las necesidades del capital» (Montagut, 2000, p. 63) y, debido a ello, empieza a cuestionarse su legitimidad. Se alude esta consideración de crisis al desempleo, al cambio de las formas de producción y de consumo, a un dualismo social acentuado, una política económica conservadora y «una creencia generalizada de la falta de alternativas» (Montagut, 2000:64). Esping-Andersen (2000) se apoya estos argumentos considerando que la crisis no se encuentra tanto dentro del Estado del Bienestar, sino en los otros dos pilares que configuran los regímenes de bienestar de una sociedad: el mercado y la familia. La crisis del Estado del Bienestar y la amenaza existente en torno a su futura sostenibilidad financiera proviene de la baja fecundidad, las jubilaciones anticipadas, la creciente dependencia de los subsidios asistenciales, el aumento de personas pensionistas, la inestabilidad familiar, el creciente desempleo y las malas condiciones laborales y las dificultades de conciliación laboral y familiar que sufren las mujeres en la actualidad. Según Esping-Andersen (2000), si hablamos de crisis el Estado del Bienestar es porque éste no ha sabido transformarse a la luz de estos cambios estructurales. 
El típico Estado del Bienestar europeo parece seguir presuponiendo el tipo de orden familiar y laboral que reinaba en la época dorada de nuestros padres y abuelos. Sigue presuponiendo una familia estable, con un varón cabeza de familia que tiene un puesto de trabajo permanente, y una madre a tiempo completo, dedicada las veinticuatro horas a la atención social de los hijos y de los padres ancianos. $\mathrm{Y}$ sigue presuponiendo $-\mathrm{y}$, en muchos países, también sustentando- aquellos rasgos del mercado de trabajo que garantizaban al varón cabeza de familia que se hallaba en los inicios de la madurez la máxima seguridad laboral y un salario familiar suficiente. En tanto el Estado del Bienestar actual siga manteniendo tales presupuestos podemos hablar legítimamente de una «crisis del Estado del Bienestar». (Esping-Andersen, 2000, p. 13).

\subsubsection{Tipologías de Estado del Bienestar}

Cada Estado-nación procuró un modelo de protección social adaptado a sus realidades concretas. Esta circunstancia conlleva que existan expertos/as que elaboren tipologías para describir las características principales de los Estados del Bienestar a nivel internacional. En este trabajo vamos a analizar en detalle la clasificación de Esping-Andersen (1990) ${ }^{5}$ y la aportación a ésta de Moreno (2003), ya que se incorpora el modelo de bienestar mediterráneo y el papel que ocupan las mujeres en él.

Esping-Andersen (1990) diferencia entre Estado del Bienestar y régimen de bienestar, prefiriendo esta última categoría porque está más relacionada con un concepto más amplio que abarcaría las relaciones entre el Estado y la economía, no centrándose únicamente en la política social. Tras esta aclaración, elabora una tipología distinguiendo tres tipos de regímenes de bienestar: conservador, liberal y socialdemócrata, regímenes cualitativamente diferenciados en función de la incidencia gradual que muestren la familia, el Estado o el mercado en la provisión de bienestar a la población que reside en un territorio determinado. El autor advierte que estos modelos no son puros y que cada uno de los países puede pertenecer predominantemente a un modelo, pero recoger elementos de los demás.

El primer tipo, el modelo liberal, es un modelo de protección residual mínimamente desmercantilizado ${ }^{6}$. Los requisitos para acceder a los derechos

${ }^{5}$ Se eliminan de este apartado referencias a otro tipo de tipologías como la de Mishra (1990) bajo la premisa de que la cuestión principal relacionada con la hipótesis central del trabajo es poder conocer una clasificación clásica sobre la que incorporar la perspectiva de género a través de los cuestionamientos feministas.

6 Por desmercantilización, Esping-Andersen (1990:60) entiende «el grado en que los individuos o las familias pueden mantener un nivel de vida socialmente aceptable independientemente de su participación en el mercado». 
sociales son estrictos, con subsidios precarios asociados al estigma y circunscritos a la población más pobre. Los países que mejor representan este modelo son EE. UU., Canadá y Australia. Este tipo de régimen minimiza los efectos de la desmercantilización, limita con efectividad el alcance de los derechos sociales y construye un orden de estratificación que es una mezcla de una relativa igualdad de pobreza entre los beneficiarios de la protección social, de un bienestar social para mayorías diferenciado por el mercado (Esping-Andersen, 1990, pp. 47-48).

En segundo lugar, encontramos el modelo corporativista-conservador. En él se conservan las diferencias de estatus, por lo que su impacto redistributivo es insignificante. La Seguridad Social discrimina a las mujeres que no trabajan "los centros de día y otros servicios de ayuda similares están subdesarrollados, el principio de la subsidiariedad sirve para destacar que el Estado intervendrá solamente cuando se acabe la capacidad de la familia para atender a sus miembros» (Esping-Andersen, 1990, p. 48). Los regímenes de bienestar de Austria, Francia, Alemania e Italia están integrados en esta definición.

El tercer modelo es el modelo socialdemócrata. Es el más basado en la consecución de la igualdad, promoviendo prestaciones equiparables al mercado y no de carácter mínimo. La desmercantilización y la universalización son elevadas, permitiendo a las trabajadoras y los trabajadores participar de sus derechos sociales de forma igualitaria con las clases más pudientes. Los países escandinavos se muestran como el conjunto de países a la cabeza en materia de protección social hacia su población.

A modo de resumen, el Cuadro 1 establece las principales características de los tres regímenes de Estados del Bienestar.

Cuadro 1. Características de los diferentes regímenes

\begin{tabular}{|l|l|l|l|}
\hline & Modelo Liberal & Modelo Socialdemócrata & Modelo Conservador \\
\hline $\begin{array}{l}\text { Papel de: } \\
\text { - La familia } \\
-\quad \text { El mercado }\end{array}$ & $\begin{array}{l}\text { Marginal } \\
\text { Central } \\
\text { Marginal }\end{array}$ & $\begin{array}{l}\text { Marginal } \\
\text { Marginal } \\
\text { Central }\end{array}$ & $\begin{array}{l}\text { Central } \\
\text { Marginal } \\
\text { Subsidiario }\end{array}$ \\
\hline $\begin{array}{l}\text { Estado del Bienestar } \\
\text { Modelo de solidaridad } \\
\text { predominante }\end{array}$ & Individual & Universal & $\begin{array}{l}\text { Parentesco } \\
\text { Corporativismo } \\
\text { Estatismo } \\
\text { Familia }\end{array}$ \\
\hline $\begin{array}{l}\text { Lugar de solidaridad } \\
\text { predominante }\end{array}$ & Mercado & Estado & Familia \\
\hline $\begin{array}{l}\text { Grado de desmercanti- } \\
\text { lización }\end{array}$ & Mínimo & Máximo & $\begin{array}{l}\text { Alto (para el cabeza de } \\
\text { familia) }\end{array}$ \\
\hline Ejemplos modales & Estados Unidos & Suecia & Alemania, Italia \\
\hline
\end{tabular}


Las tipologías establecidas por Esping-Andersen (1990, 2000) han sido las más referenciadas a partir de los años 90. En el siguiente epígrafe se tratan las críticas que las expertas feministas le realizan. Mientras tanto, existen una serie de modificaciones que han ido sufriendo estos estudios. En este sentido, es preciso destacar las incorporaciones teóricas que añaden un cuarto modelo o "vía media» de régimen de bienestar a la categorización clásica atendiendo a las condiciones específicas de los países mediterráneos, que Leibfried (1993), Moreno (1999, 2000, 2003) o Rodríguez Cabrero (1997, 2004) consideran, y que Esping-Andersen (1990) originariamente no advierte.

Para Moreno (2000), la "vía media» se encuentra entre los modelos bismarckianos y los beveridgeanos a tenor de cuatro características compartidas por los países mediterráneos que no comparten los demás países europeos. En primer lugar, las necesidades y estilos de vida diferentes. Moreno (2000) advierte una serie de particularidades por las que los países mediterráneos conservan una cultura diferenciada del resto de Europa, como la distribución de bienestar entre los miembros de una misma unidad convivencial, la concentración de viviendas en propiedad de las personas mayores, o la tardía emancipación de las y los jóvenes. La microsolidaridad familiar sería un segundo punto a tener en cuenta, ya que la familia representa un elemento central para la provisión de bienestar entre sus miembros. Aquí surge la figura de las mujeres como procuradoras de microsolidaridad, de hecho, el autor les denomina supermujeres meridionales, e incide en la idea de que:

los niveles afectivos entre los miembros familiares conllevan no solo la trasmisión de actitudes, conocimientos, percepciones, valores, reflejados en los altos niveles de ayuda mutua en el seno de los hogares. Todo ello conforma una visión social entre los ciudadanos. Es precisamente en el seno del microcosmos de solidaridad familiar donde el rol de la mujer ha sido -y continúa siendodeterminante en el conjunto de las políticas de bienestar. (Moreno, 2000, p. 101).

Otro punto de esta "vía media» es la conjunción entre universalismo y selectividad. Moreno (2000) apunta que esta característica es consecuencia de la especificidad de los mercados de trabajo, ya que se crea una fuerte polaridad entre tres grupos de trabajadores/as. Por un lado, estarían aquellos con un alto nivel de protección, en otro lado, los habitantes de una periferia laboral (entran y salen de la zona de seguridad) y, en último término, los/as trabajadores/as marginales que suelen estar empleados dentro de la economía sumergida y que, como consecuencia, no poseen estabilidad suficiente para generar derechos contributivos.

En cuarto y último lugar, cabría señalar una característica paradójica de los regímenes de bienestar mediterráneo que algunos autores apuntan (Trifiletti, 1999; Fernández Cordón y Tobío Soler, 2005), que consiste en la conjunción de unas 
tasas de fecundidad bajas con una también baja actividad laboral, lo que supone un condicionante estructural para la sostenibilidad de este tipo de regímenes de bienestar.

\subsection{El Estado del Bienestar en España: contexto, origen y periodos fundamentales}

Si en algo están de acuerdo los autores/as mencionados que abogan por un cuarto modelo de régimen del bienestar, es en dictaminar que el Estado del Bienestar en España se desarrolla de manera tardía y, al igual que los demás países mediterráneos, después de sufrir durante un tiempo regímenes políticos dictatoriales.

Asimismo, aunque existen debates en torno a la fecha concreta del surgimiento del Estado del Bienestar en España, se determina su origen en torno a los años 70 (Rodríguez Cabrero, 2004), ya que en esos años se produce una apertura franquista que genera un cierto crecimiento económico semi-fordista. Además, se desarrollan también los principios de la actual Seguridad Social. Rodríguez Cabrero (2004) disiente así de aquellos/as que señalan el origen del Estado del Bienestar español como resultado de la suma entre la democracia y la industrialización, puesto que la democracia tardará unos años en llegar y ya comienzan a efectuarse medidas en torno a la protección social. En cuanto a la industrialización, históricamente es sabido que en los países del sur este proceso es mucho más lento que en el resto de Europa.

Existen dos periodos clave en la consolidación del Estado del Bienestar en España:

El periodo comprendido entre 1960 y 1975 en el que se produce una apertura de la economía española y un proceso de modernización capitalista derivados de la crisis de autarquía que venía sufriendo el régimen franquista desde la década anterior. Esta situación dio paso a una combinación no exenta de contradicciones entre políticas económicas de corte keynesiano y una estructura política despótica. Una de las características propias de este periodo es la introducción de técnicas fordistas de división y organización del trabajo de los sectores punteros de la economía española. Al ser técnicas basadas en la productividad y la eficiencia técnica, demandan sistemas de protección social que garanticen un funcionamiento regular del mercado de trabajo. La redefinición del marco de relaciones laborales se conforma como la segunda característica de este primer periodo, en el que surge un tipo de negociación colectiva fuertemente controlada, que estimula indirectamente ciertas demandas sociales a la vez que pretende canalizar los conflictos sociales. En tercer lugar, destacamos el nuevo modelo económico basado en el consumo de masas que va a exigir un sistema de consumo colectivo centrado en el desarrollo de las prestaciones sociales monetarias $y$, en menor medida, en los servicios redistributivos como educación y vivienda, donde la asistencia sanitaria es una excepción parcial. 
En este período también se pueden observar estrategias de protección fundamentadas en la desprovisión del bienestar social de las mujeres. Un ejemplo de ello se encuentra en la aprobación de la Ley 193/1963 de Bases de la Seguridad Social que vincula los derechos sociales con los rendimientos de trabajo. Esta consagración de los derechos a los beneficios de la Seguridad Social reifica la ideología de la familia tradicional (Sainsbury, 1994), donde el sujeto de derechos es el cabeza de familia (mayoritariamente hombres) y los demás miembros de la unidad convivencial disfrutan de ellos subsidiariamente (mujeres y niños/as).

El segundo periodo se corresponde con la democratización del país (tras la muerte de Franco en 1975) hasta la actualidad. En este periodo se cumple el clásico binomio de establecimiento de los Estados del Bienestar europeos (democracia parlamentaria y capitalismo industrial). España inaugura la democracia gracias a la aprobación de la Constitución. El modelo se consolida paulatinamente tras el empuje e influencia generada por la incorporación en la UE en 1986. En esta etapa se realiza un esfuerzo redistributivo no exento de contradicciones ya que, si bien avanza el proceso de universalización de la provisión de bienestar al ámbito educativo, sanitario, de prestaciones sociales y de pensiones, también se presentan las presiones privatizadoras de los años 80 y el debilitamiento de la capacidad de control de los Estados sobre los caudales financieros fruto de la globalización económica (Del Pino y Rubio Lara, 2016). En contexto genera políticas de contención del gasto social y de la intensidad protectora. Así, el Estado del Bienestar no acaba de desarrollarse completamente porque cuando aparecen las condiciones propicias para su expansión, este se ve afectado por cambios estructurales que dificultan su evolución. Entre estos cambios, Palier (2016, p. 77) destaca el proceso de desindustrialización, el desempleo estructural y el envejecimiento de la población. Por su parte, Rodríguez Cabrero (2004) expone que estas contradicciones señaladas anteriormente se agudizan, generando diferentes consecuencias:

Una universalización desigual de los diferentes servicios y prestaciones económicas, que va acompañada de una contención de la intensidad protectora. Esta contención coincide con los períodos en los que tiene lugar un fuerte crecimiento económico y un ajuste normativo del gasto en desempleo. Si la década de los 80 supone la culminación del proceso histórico de universalización iniciado en las dos décadas precedentes, los años 90 se definen por la contención del gasto social y, con ello, la reducción de la intensidad protectora. Con dinámica semejante y ya en el siglo XXI (Moreno y Marí-Klose, 2016) el gobierno de José Luis Rodríguez Zapatero desarrolla políticas sociales en beneficio de diferentes grupos de población como juventud (ayudas al alquiler para favorecer su emancipación), personas dependientes (Ley de Promoción de la Autonomía Personal y Atención a las personas en situación de dependencia ya las familias), o las mujeres y su participación laboral y conciliación (Ley de lgualdad). Estas medidas supusieron una modesta expansión del gasto frenadas por la crisis económica iniciada en 2007. 
La amplia politización de las políticas sociales es otro de los procesos que se dibujan en este periodo en la medida en que no solo son objeto de negociación política, desde el Pacto de la Moncloa a finales de 1977 hasta el Pacto de Toledo en 1995 y su desarrollo posterior en 2003, sino también porque las políticas sociales son centro permanente de conflicto social.

La descentralización se conforma como la tercera consecuencia del periodo, se produce un creciente protagonismo de las comunidades autónomas en la planificación y ejecución de las políticas sociales, reduciéndose así la capacidad de las administraciones centrales en el control de la política social, lo que plantea problemas de equidad territorial. Solamente la Seguridad Social ha permanecido como eje unificador de la política social en su ámbito específico.

\section{CRÍtiCAS A LA EVOLUCIÓN DEL ESTADO DEL BIENESTAR DESDE UNA PERSPECTIVA DE GÉNERO}

Una vez establecidos los mimbres sobre los cuales se asentaron las políticas sociales europeas, y tras hacer especial referencia al Estado del Bienestar español, este apartado tiene la intención de acercarse al conocimiento de las principales investigaciones que han analizado, revisado y/o criticado los modelos de Estados del Bienestar vistos con anterioridad.

Las políticas sociales españolas implementadas bajo el amparo del Estado del Bienestar han mantenido un sesgo de género desde su gestación hasta la actualidad. Este sesgo "recorre las distintas instituciones sociales, hace que la vida de las mujeres transcurra por vías muy distintas a las de los hombres, sin que las políticas sociales tiendan en lo fundamental a corregir las desigualdades por razones de sexo» (Carrasco, 1997, p. 13). Nos encontramos, por tanto, ante un error sistemático que perjudica el acceso al bienestar social de las mujeres, hasta el punto de que se podría tratar como una medida de expropiación del bienestar.

En concreto, este epígrafe hace referencia a las críticas realizadas a una de las clasificaciones más relevantes del panorama científico internacional, la realizada por Esping-Andersen en 1990 a partir de la obra The Tree Worlds of the Welfare Capitalism. Las críticas que se introducen en este epígrafe giran en torno a varias cuestiones. Por un lado, las que están orientadas a la escasa profundización del ámbito familiar como proveedor de bienestar, su relación con la estratificación social y las dificultades de acceso al mercado de trabajo que padecen las mujeres. Por otro lado, se analiza un segundo grupo de críticas relacionadas con el concepto de ciudadanía implícito en esta obra y cuyo origen es la propuesta por T. H. Marshall (1950). Un último apartado revisa las críticas basadas en el concepto de desmercantilización. 


\subsection{Madres, empleadas y ciudadanas invisibilizadas}

En su estudio clásico, Esping-Andersen (1990) pasa por alto la influencia de los Estados del Bienestar en hombres y en mujeres de forma diferenciada. Desarrolla una tipología imprescindible a la hora de estudiar los modelos de protección social europeos, pero permanece "ciega» u "olvidadiza» respecto a la categoría género, una circunstancia que motiva que, tras su publicación, se revise y critique desde corrientes de pensamiento feministas. Mientras que la clasificación de EspingAndersen (1990) es sensible a las desigualdades de clase que se producen dentro del mercado laboral entre los trabajadores asalariados, no hay un análisis en los mismos términos en cuanto al género.

Esping-Andersen (1990) enumera los tres elementos fundamentales en la provisión de bienestar de la población: el mercado, el Estado y la familia. El inconveniente que encuentra la producción feminista es que se ejerce un mayor hincapié en examinar la relación Estado-mercado, y se profundiza mucho menos en la labor e influencia de la familia. Esta carencia analítica conlleva un desconocimiento por parte de las políticas públicas en torno al desigual grado de responsabilidad que soportan mujeres y hombres en la esfera doméstica. Son autoras que apuestan por conocer en qué medida las políticas sociales favorecen o no la corresponsabilidad en el entorno familiar para ayudar a superar las desigualdades entre sus miembros. Además,

hay contextos donde la situación familiar se vuelve determinante: si se considera, por ejemplo, una mujer casada, ama de casa a tiempo completo, su relación con el Estado como posible cliente de ayudas sociales se establece normalmente a través de su marido (que es quien participa en el mercado laboral o tiene una relación laboral más estable). (Carrasco, 1997, p. 31).

Dolors Comas d'Argemir (2000), al igual que Cristina Carrasco (1997), participa de estas críticas y añade que la invisibilidad que todavía permanece a nuestro alrededor en relación al trabajo reproductivo y la asunción mayoritaria por parte de las mujeres, obedece a tres razones fundamentales. La primera razón se debe a que el trabajo reproductivo se mantiene predominantemente en el ámbito familiar, lo que dificulta su visibilización. Las instituciones sociales suelen desarrollar políticas de cara a intervenir sobre esta materia, pero estas son insuficientes porque ayudan o complementan la labor familiar, no sustituyen plenamente el trabajo realizado dentro de la familia por las mujeres. Si existiese verdadera conciencia política de intervenir sobre este asunto, deberían desplegarse redes de apoyo desde la iniciativa pública que sustituyesen o redujesen sustantivamente la carga de trabajo reproductivo que soportan las mujeres, lo que supondría una gran inversión de capital. La segunda razón está relacionada con las resistencias a concebir las 
tareas domésticas y de cuidados como trabajo «las actividades implicadas en el apoyo y el cuidado suponen la existencia de amor pero también de trabajo, de obligación moral pero también de materialidad» (Comas, 2000, p. 189). La tercera valoración esgrimida por la autora está muy relacionada con la anterior, y radica en asumir que culturalmente se siguen concibiendo las actividades de los cuidados como inherentes a la vinculación afectiva, y por tanto suscritas a sus máximas garantes, las mujeres. Dentro de la familia, las mujeres, al responsabilizarse del trabajo reproductivo, asumen estas actividades como naturales y no las conciben como trabajo. Generalmente se interioriza que las mujeres poseen una especial predisposición para estas tareas y use nos esconde que el aprendizaje es un componente básico en la asunción de estas actividades» (Comas d’Argemir, 2000, pp. 190-191).

Un vistazo a las estadísticas que ofrece la Encuesta de Usos del Tiempo (Tabla 1), elaborada por el Instituto Nacional de Estadística (INE), nos permite poner de relieve la desigual distribución de las tareas que realizan hombres y mujeres en los hogares. Como se puede observar, existe un notable desequilibrio en el uso del tiempo en varios aspectos. Uno de ellos es el tiempo empleado a trabajo remunerado, donde los hombres dedican, en promedio, casi cinco puntos más que las mujeres. Pero la gran brecha se encuentra en el uso del tiempo en tareas propias del hogar y la familia. En este caso, las mujeres dedican una proporción de más de 10 puntos que los hombres. En un día, en promedio, las mujeres dedican un total de 4 horas y 7 minutos, mientras que los hombres únicamente lo hacen en 1 hora y 54 minutos.

Tabla 1. Distribución de actividades en un día promedio. Promedio de tiempo según sexo

\begin{tabular}{|l|l|l|l|l|}
\multicolumn{1}{c|}{} & \multicolumn{3}{c}{ Tiempo } & \multicolumn{2}{c|}{ Porcentaje } \\
\cline { 1 - 1 } \multicolumn{1}{c|}{ Tipo de actividad } & Mujeres & Hombres & Mujeres & Hombres \\
\hline Cuidados personales & $11: 26$ & $11: 33$ & $47,64 \%$ & $48,13 \%$ \\
\hline Trabajo remunerado & $1: 54$ & $3: 04$ & $7,92 \%$ & $12,78 \%$ \\
\hline Estudios & $0: 39$ & $0: 39$ & $2,71 \%$ & $2,71 \%$ \\
\hline Hogar y familia & $4: 07$ & $1: 54$ & $17,15 \%$ & $7,92 \%$ \\
\hline Trabajo voluntario y reuniones & $0: 16$ & $0: 12$ & $1,11 \%$ & $0,83 \%$ \\
\hline Vida social y diversión & $1: 01$ & $1: 04$ & $4,24 \%$ & $4,44 \%$ \\
\hline Deportes y actividades al aire libre & $0: 37$ & $0: 52$ & $2,57 \%$ & $3,61 \%$ \\
\hline Aficiones e informática & $0: 24$ & $0: 44$ & $1,67 \%$ & $3,06 \%$ \\
\hline Medios de comunicación & $2: 30$ & $2: 43$ & $10,42 \%$ & $11,32 \%$ \\
\hline $\begin{array}{l}\text { Trayectos y empleo del tiempo no espe- } \\
\text { cificado }\end{array}$ & $1: 06$ & $1: 14$ & $4,58 \%$ & $5,14 \%$ \\
\hline
\end{tabular}


Cabe señalar también que las mujeres emplean menos tiempo en otras actividades relacionadas con la vida social y la diversión, los deportes y actividades al aire libre, así como aficiones varias e informática.

Adentrándonos en las tareas propias del hogar y la familia, la Tabla 2 explicita que la brecha entre mujeres y hombres en actividades que se circunscriben al ámbito familiar se debe, fundamentalmente, a las actividades culinarias, donde el uso del tiempo en el caso de las mujeres (alrededor de una hora y media al día), es prácticamente el triple que en el caso de los hombres (media hora aproximadamente), a las actividades de mantenimiento del hogar (49 minutos al día frente a 17), y a la confección y cuidado de ropa (23 minutos frente a uno).

Tabla 2. Distribución de actividades relacionadas con el hogar y la familia en un día promedio. Promedio de tiempo según sexo

\begin{tabular}{|l|l|l|l|l|}
\hline \multicolumn{1}{|c|}{ Tipo de actividad } & \multicolumn{3}{c|}{ Tiempo } & \multicolumn{3}{c|}{ Porcentaje } \\
Hogaj y familia (Total) & $4: 07$ & $1: 54$ & $17,15 \%$ & $7,92 \%$ \\
Actividades para el hogar y la familia no & & & & \\
especificadas & $0: 15$ & $0: 04$ & $1,04 \%$ & $0,28 \%$ \\
Actividades culinarias & $1: 24$ & $0: 26$ & $5,83 \%$ & $1,81 \%$ \\
Mantenimiento del hogar & $0: 49$ & $0: 17$ & $3,40 \%$ & $1,18 \%$ \\
Confección y cuidado de ropa & $0: 23$ & $0: 01$ & $1,60 \%$ & $0,07 \%$ \\
Jardinería y cuidado de animales & $0: 07$ & $0: 18$ & $0,49 \%$ & $1,25 \%$ \\
Construcción y reparaciones & $0: 01$ & $0: 06$ & $0,07 \%$ & $0,42 \%$ \\
Compras y servicios & $0: 31$ & $0: 20$ & $2,15 \%$ & $1,39 \%$ \\
Gestiones del hogar & $0: 01$ & $0: 01$ & $0,07 \%$ & $0,07 \%$ \\
Cuidado de niños & $0: 32$ & $0: 18$ & $2,22 \%$ & $1,25 \%$ \\
Ayudas a adultos miembros del hogar & $0: 04$ & $0: 02$ & $0,28 \%$ & $0,14 \%$ \\
\hline
\end{tabular}
Fuente: Elaboración propia a partir de Encuesta de Usos del Tiempo 2009-2010.

Por tanto, las mujeres asumen y se responsabilizan de una gran carga de actividades relacionadas con el hogar y la familia, tareas que se caracterizan por su invisibilidad, y que tienen efectos negativos sobre la participación en el mercado laboral, entre otras cuestiones.

Esping-Andersen en obras posteriores $(2000,2008)$ y tras advertir las críticas feministas a sus publicaciones, ahonda en el estudio de las familias introduciendo el trabajo reproductivo de las mujeres en sus análisis y las consecuencias negativas que suponen, para ellas y para el conjunto de la sociedad, asumir en exclusiva este trabajo. Por esta razón, establece para sus diferentes regímenes del bienestar los términos de familiarismo y desfamiliarización. 
Por familiarismo entiende «aquel [Estado del Bienestar] que asigna un máximo de obligaciones de bienestar a la unidad familiar» (Esping-Andersen, 2000, p. 66). Y por desfamiliarización «aquellas políticas que reducen la dependencia individual de la familia, que maximizan la disponibilidad de los recursos económicos por parte del individuo independientemente de las reciprocidades familiares y conyugales» (Esping-Andersen, 2000, p. 66). Estas cuestiones, confirma el autor, tienen un carácter gradual, luego habrá países con un mayor o menor grado de familiarismo. Desde este punto, aboga por una necesaria desfamiliarización que repercuta positivamente en el bienestar de los miembros de una misma unidad familiar al debilitar la dependencia de unos frente a otros. Generalmente, los países más desfamiliarizados se corresponden con los que pertenecen al régimen socialdemócrata (Dinamarca, Noruega, Suecia) y los más familiaristas los comprendidos dentro de la Europa meridional (España, Italia, Grecia, Portugal).

Esping-Andersen (2008), atendiendo a estos conceptos, y contextualizando el análisis dentro del Estado español, reflexiona sobre las consecuencias negativas que conlleva en nuestro país mantener un alto grado de familiarismo; estas consecuencias inciden en varios aspectos:

El primer aspecto hace referencia a que el familiarismo produce un retroceso de la oferta de trabajo para las mujeres. Como se puede observar en el Gráfico 1, la tasa de actividad de las mujeres ha permanecido sistemáticamente por debajo de la de los hombres. Aunque la tasa de actividad femenina ha aumentado considerablemente durante las décadas de los 80, 90 y 2000, a partir del año 2010 se ha estancado, manteniéndose aún unas diferencias de en torno al $10 \%$.

Gráfico 1. Evolución de la tasa de actividad según sexo

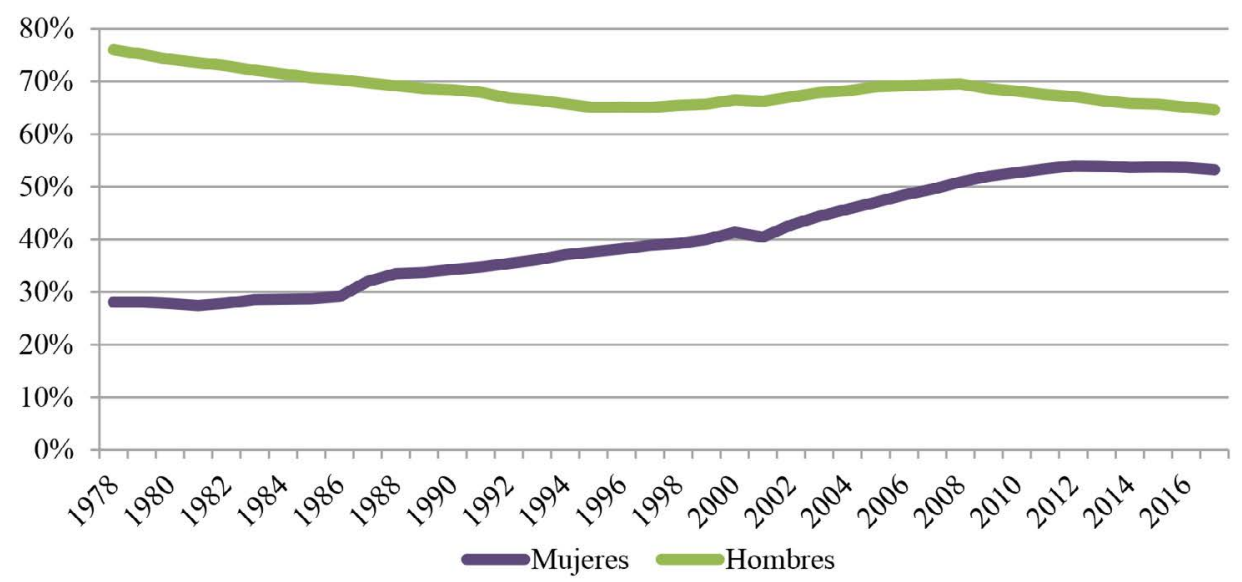
Fuente: Elaboración propia a partir de Encuesta de Población Activa. 
Al observar las tasas de paro, las diferencias persisten, aunque con una evolución más irregular. En este caso, podemos ver en el Gráfico 2 cómo la tasa de paro femenina fluctúa con los cambios propios de los ciclos económicos, pero manteniendo siempre un nivel superior a la tasa de paro masculina. Entre los años 2009 y 2013, las diferencias han disminuido notablemente, si bien es cierto que esto se ha debido principalmente a la destrucción de empleos en sectores con una sobrerrepresentación masculina, como es el caso de la construcción. No obstante, a partir de 2013, coincidiendo con el inicio de la bajada de la tasa de paro, las diferencias se han ido ampliando hasta la actualidad.

Gráfico 2. Evolución de la tasa de paro según sexo

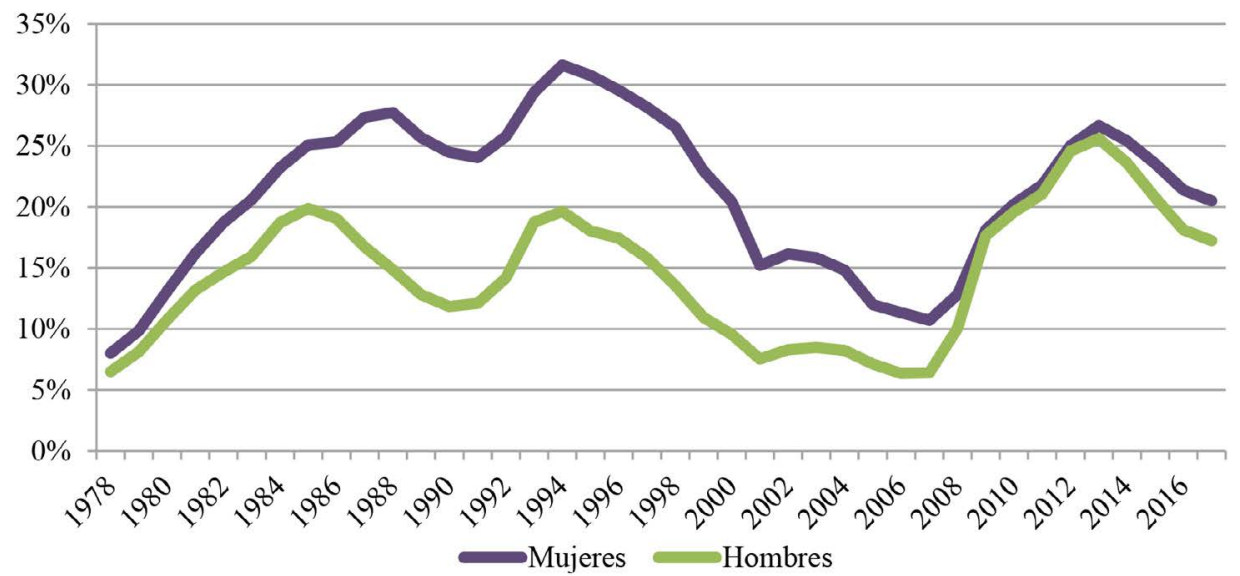

Fuente: Elaboración propia a partir de Encuesta de Población Activa.

Esta circunstancia se aprecia aún más en aquellas mujeres que poseen una formación escasa, ya que aquellas que poseen una alta cualificación mantienen tasas de actividad y de paro que paulatinamente se van equiparando a las de los hombres. Este hecho se puede contrastar en el Gráfico 3, donde se muestra las diferencias entre las tasas de actividad de mujeres y hombres según el nivel de estudios alcanzado. Así, las mujeres con estudios superiores registran una tasa de actividad prácticamente igual a la de los hombres. Sin embargo, las mujeres que poseen una baja cualificación continúan manteniendo roles de género tradicionales y, gran parte de ellas, permanecen en sus hogares responsabilizándose casi en exclusiva del trabajo reproductivo. Esta situación supone una «enorme reserva de oferta de trabajo potencial» (Esping-Andersen, 2008, p. 33). Por ello, las mujeres que cuentan con unos estudios de primera etapa de educación secundaria (equivalente a la Educación Secundaria Obligatoria) o inferior, registran unas tasas de actividad mucho menores que los hombres que tienen un nivel educativo equivalente. 
Gráfico 3. Tasas de actividad según nivel de estudios y sexo, año 2016

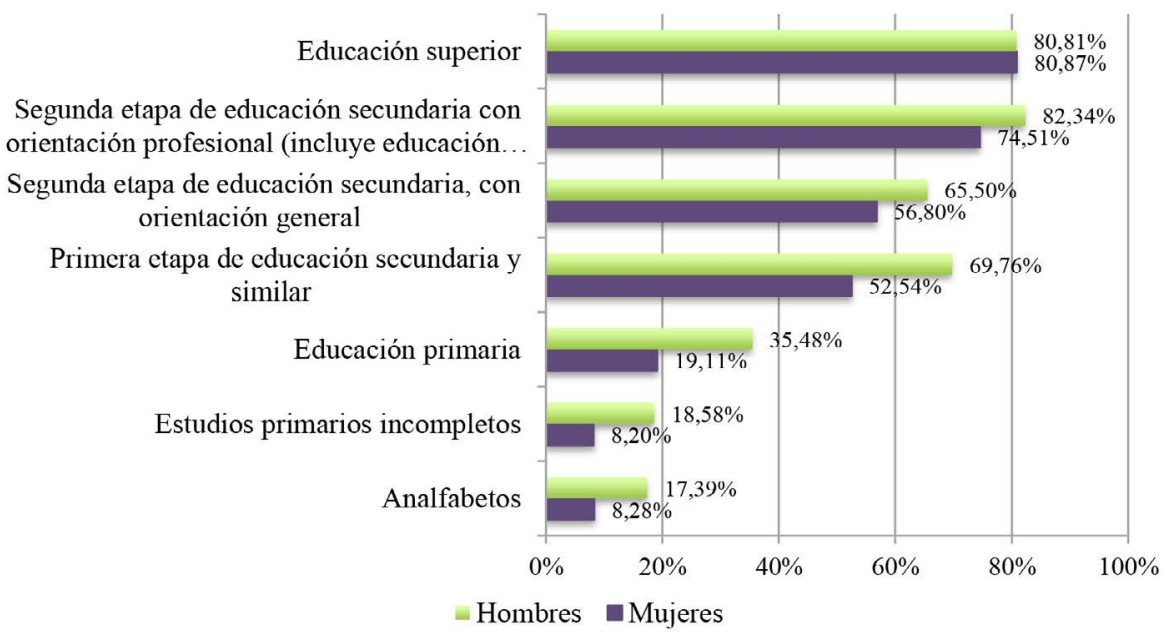

Fuente: Elaboración propia a partir de Encuesta de Población Activa.

Este comportamiento se puede comprobar de forma similar en las tasas de paro, representadas en el Gráfico 4. En este caso, la tasa de paro femenina es incluso inferior que la masculina para las mujeres que cuentan con estudios superiores. No obstante, no se encuentra la misma lógica en los estudios secundarios y primarios, que ofrecen distintas interpretaciones. En cualquier caso, las mujeres menos cualificadas, es decir, aquellas que no han terminado los estudios primarios o se les considera analfabetas, cuentan con una tasa de paro muy superior a la de los hombres de estas categorías.

Gráfico 4. Tasas de actividad según nivel de estudios y sexo, año 2016

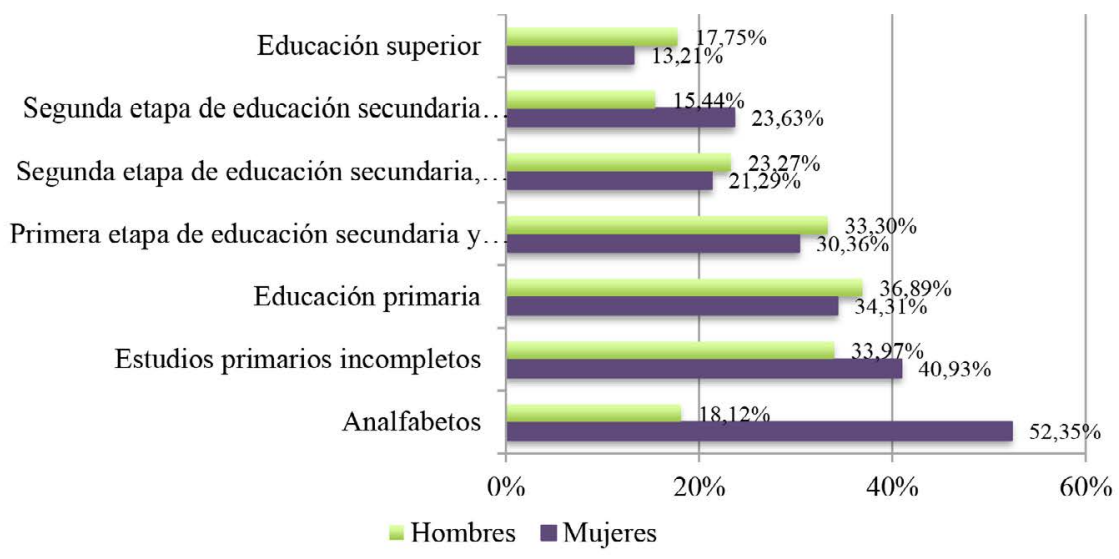

Fuente: Elaboración propia a partir de Encuesta de Población Activa. 
Continuando con las consecuencias negativas que supone el mantenimiento de un régimen del bienestar familiarista, Esping-Andersen (2008) destaca cómo este tipo de régimen dificulta el crecimiento económico, advirtiendo que, si la entrada de las mujeres al mercado laboral fuese mayor de lo que es actualmente, el PIB (Producto Interior Bruto) aumentaría hasta un $15 \%$. No es el objetivo de este trabajo realizar un ejercicio empírico que ponga de relieve este hecho, pero basta con revisar la literatura existente para afirmar que la falta de participación de las mujeres en el mercado de trabajo es un lastre en términos de crecimiento económico. Este argumento es compartido por Aguirre et al. (2012), que estiman que la equiparación de los niveles de empleo de las mujeres a los de los hombres supondría un incremento del PIB del 5\% para la economía estadounidense, y de un 9\% para el caso japonés. De la misma forma, Cuberes y Teignier (2014, p. 268) concluyen que la desigualdad de género tiene un impacto negativo sobre el crecimiento económico, algo que también es apuntado por varios informes de instituciones como el Fondo Monetario Internacional (Elborgh-Woytek, et al., 2013) o la OCDE (OECD, 2014, p. 13). Una vez más, el nivel educativo de las mujeres marca la diferencia. En este sentido, Dollar y Gatti (1999, p. 19) apuntan que la escolarización femenina en niveles de educación secundaria está positivamente relacionada con el crecimiento económico.

El tercer aspecto habla de cómo los regímenes familiaristas generan polarización social en la población (Esping-Andersen, 2008). La mayor participación laboral de las mujeres está muy concentrada en las clases medias, media-altas, pero, en las clases bajas la tasa desciende considerablemente.

Esto origina la existencia de hogares con dos ingresos en los niveles altos, mientras que los hogares con menores niveles de cualificación de sus miembros tienden a tener, además, un único ingreso (...) agravando las consecuencias de la actual ola de precarización del empleo y del crecimiento de las desigualdades económicas, con lo que la brecha social se profundiza aún más. (EspingAndersen, 2008, p. 34).

\subsection{El sesgo de la ciudadanía marshalliana}

Según Marshall (1950), el concepto de ciudadanía consta de tres elementos fundamentales: los derechos civiles, los derechos políticos y los derechos sociales. Estos se han ido configurando a través de los siglos XVIII, XIX y XX.

El primer elemento lo constituyen los derechos civiles: la libertad de la persona, la libertad de expresión, de pensamiento, de religión, de propiedad, entre otros. También se denominan derechos civiles los referidos a establecer contratos válidos y el derecho a la justicia. Las instituciones fundamentales que se van a encargar 
de garantizar su satisfacción son los Tribunales de Justicia. Aunque el propio autor entiende que históricamente estos derechos se entremezclan en diferentes instituciones, podemos afirmar que los derechos civiles se forman alrededor del siglo XVIII.

Tomando a modo de ejemplo el derecho a la propiedad, podemos poner de relieve la situación de desigualdad con los datos de titularidad de explotaciones agrarias que se muestran en la Tabla 3. Como se puede observar, las mujeres tienen una proporción mucho menor de propiedades de este tipo, tanto en términos de número de explotaciones como en número de hectáreas.

Tabla 3. Datos de propiedad de explotaciones agrarias según sexo del titular ${ }^{7}$

\begin{tabular}{|l|l|l|}
\hline \multicolumn{1}{|c|}{ Indicador } & \multicolumn{1}{c|}{ Mujeres } & \multicolumn{1}{c|}{ Hombres } \\
\hline Número de explotaciones agrarias & 283.291 & 646.403 \\
\hline Proporción de explotaciones agrarias & $28,62 \%$ & $65,31 \%$ \\
\hline Hectáreas & 4.490 .517 & 15.020 .723 \\
\hline Proporción de hectáreas & $14,67 \%$ & $49,06 \%$ \\
\hline
\end{tabular}

Fuente: Censo Agrario 2009, INE.

Además, cabe destacar la falta de datos disponibles con perspectiva de género para estadísticas importantes en este aspecto. Este es el caso de la Estadística Registral Inmobiliaria, realizada por el Colegio de Registradores de la Propiedad, Bienes Inmuebles y Mercantiles de España, cuyos resultados no tienen en cuenta la desagregación por sexo de los distintos resultados expuestos en sus anuarios ${ }^{8}$.

Los derechos políticos, segundo elemento fundamental que otorga la ciudadanía, se pueden datar hacia el siglo XIX. Están constituidos por aquellos derechos relacionados con la participación en el ejercicio del poder político: bien como miembro de un cuerpo investido de autoridad política, o bien como elector/a de los mismos.

Si hablamos de autoridad, las mujeres han estado infrarrepresentadas en los diferentes niveles de gobierno desde los orígenes del sistema democrático. Por tomar un ejemplo, según datos del Instituto de la Mujer y para la Igualdad de Oportunidades, desde el año 2011 el porcentaje de mujeres en el equipo de gobierno del Estado es de entre el $28 \%$ y el $36 \%$, una proporción que queda lejos de los objetivos de paridad. Si se extiende el análisis a la participación en cargos ejecutivos en los principales partidos políticos, solo un $37,5 \%$ están ocupados por

7 En la tabla no se incluyen los datos correspondientes a propiedades cuya titularidad no corresponde a personas físicas. No obstante, los porcentajes se han obtenido teniendo en cuenta el total de explotaciones agrarias, por lo que el total de ambos sexos no suma 100.

8 Para consultar los informes, ver <http://www.registradores.org/portal-estadisticoregistral/estadisticas-de-propiedad/estadistica-registral-inmobiliaria/>. 
mujeres $^{9}$. La Tabla 4 muestra la participación de mujeres en órganos superiores y altos cargos en la Administración General del Estado para los años 1995 y 2015. Como se puede comprobar, en ninguno de los niveles se llega a la paridad, siendo el promedio de mujeres del $31,2 \%$ en este tipo de cargos para el año 2015 . No obstante, hay una diferencia sustancial a nivel temporal, ya que se ha doblado la presencia de mujeres en este tipo de cargos en los últimos 20 años.

Tabla 4. Proporción de mujeres en órganos superiores y altos cargos en la Administración General del Estado, años 1995 y 2015 (\%)

\begin{tabular}{|l|l|l|}
\hline \multicolumn{1}{|c|}{ Nivel } & \multicolumn{1}{c|}{1995} & \multicolumn{1}{c|}{$\mathbf{2 0 1 5}$} \\
\hline Gobierno & $20 \%$ & $30,8 \%$ \\
\hline Secretarías de Estado & $25 \%$ & $20,0 \%$ \\
\hline Subsecretarías & $9,1 \%$ & $33,9 \%$ \\
\hline Direcciones Generales & $13,8 \%$ & $30,2 \%$ \\
\hline Altos cargos sin rango concreto & No disponible & $40,5 \%$ \\
\hline Total & $14,4 \%$ & $31,2 \%$ \\
\hline
\end{tabular}

Si se hace el mismo ejercicio para el sector privado, la situación es aún peor. Como muestra la Tabla 5, la proporción de mujeres en la presidencia y consejos de administración de las empresas del IBEX35 se reduce al 19,4\%. Además, los puestos de mayor poder, presidentas y vicepresidentas, solo están representados en un $5,7 \%$ y $2,4 \%$ respectivamente por mujeres. A pesar de ello, los datos disponibles desde el año 2004 permiten observar una mejora notable, ya que la presencia en general se ha incrementado desde los $2,6 \%$ hasta el $19,4 \%$. No obstante, podemos concluir que la presencia femenina en puestos de alta responsabilidad sigue estando lejos de lo deseable, tanto en el ámbito público como en el privado.

Tabla 5. Proporción de mujeres en la presidencia y en los consejos de administración de las empresas del IBEX35, años 2004 y 2015 (\%)

\begin{tabular}{|l|l|l|}
\hline \multicolumn{1}{|c|}{ Nivel } & \multicolumn{1}{c|}{$\mathbf{2 0 0 4}$} & \multicolumn{1}{c|}{$\mathbf{2 0 1 5}$} \\
\hline Presidentas & $5,4 \%$ & $5,7 \%$ \\
\hline Vicepresidentas & $2,7 \%$ & $2,4 \%$ \\
\hline Consejeras & $2,9 \%$ & $23,1 \%$ \\
\hline Consejeras secretarias & $0,0 \%$ & $0,0 \%$ \\
\hline Total & $2,6 \%$ & $19,4 \%$ \\
\hline
\end{tabular}

Fuente: Instituto de la Mujer y para la Igualdad de Oportunidades

\footnotetext{
9 Datos para el año 2016.
} 
Por otro lado, Marshall (1950) realiza un recorrido histórico de los derechos civiles argumentando que el derecho al trabajo, entendiendo este como una actividad dentro del sector productivo, constituye el derecho civil más básico. Está claro que, repasando los datos presentados anteriormente (Tablas 4 y 5), el acceso por parte de las mujeres a este derecho se ha producido más tarde, y aún hoy sigue existiendo una importante brecha de género en este sentido.

Por último, los derechos sociales se sitúan como el tercer elemento que instituye la ciudadanía. Se conforman como el conjunto de derechos más reciente, desarrollados a partir del siglo xx. Marshall (1950:27) entiende los derechos sociales como aquellos que tienen que ver con la seguridad, con un bienestar económico básico, En este sentido, cabe señalar que las mujeres mantienen una posición subordinada a la hora de percibir prestaciones sociales. Esta situación viene derivada también de su menor participación en el mercado laboral, lo que les convierte en un grupo de población más vulnerable.

En este punto, conviene señalar la limitación que supone la no disposición de datos precisos, por dos razones. En primer lugar, el hecho de que varias estadísticas tengan como unidad de análisis el hogar o la unidad convivencial (como la Encuesta de Población Activa) hace que no dispongamos de información sobre el género del titular de prestaciones. En segundo lugar, la descentralización de los sistemas de servicios sociales, cada uno con su sistema de indicadores y política de transparencia, supone una limitación a la hora de realizar un análisis conjunto del estado actual de las prestaciones sociales en España. No obstante, sirva de ejemplo la Tabla 6, en la que se puede comprobar que la proporción de mujeres que perciben pensiones o prestaciones no contributivas, es decir, aquellas que son aplicables cuando el sujeto no ha cotizado al sistema de Seguridad Social el mínimo establecido, es muy superior al $50 \%$.

Tabla 6. Proporción de mujeres beneficiarias de prestaciones no contributivas, años 2005 y 2016 (\%)

\begin{tabular}{|l|l|l|}
\multicolumn{1}{l|}{} & \multicolumn{1}{c|}{$\mathbf{2 0 0 5}$} & \multicolumn{1}{c|}{$\mathbf{2 0 1 6}$} \\
\hline Pensiones no contributivas & $71,38 \%$ & $66,66 \%$ \\
\hline Invalidez & $57,23 \%$ & $52,57 \%$ \\
\hline Jubilación & $81,71 \%$ & $77,71 \%$ \\
\hline Pensiones asistenciales & $83,38 \%$ & $85,81 \%$ \\
\hline Enfermedad & $81,66 \%$ & $85,63 \%$ \\
\hline Vejez & $89,31 \%$ & $90,18 \%$ \\
\hline Prestaciones económicas para personas con discapacidad & $80,62 \%$ & $74,74 \%$ \\
\hline Subsidio de garantía de ingresos mínimos & $90,49 \%$ & $92,83 \%$ \\
\hline Subsidio por ayuda de tercera persona & $82,5 \%$ & $86,63 \%$ \\
\hline Subsidio de movilidad y compensación por gastos de transporte & $68,89 \%$ & $68,55 \%$ \\
\hline Asistencia sanitaria y prestación farmacéutica & $57,47 \%$ & $55,84 \%$ \\
\hline \multicolumn{1}{|l}{ Fuente: Instituto de la Mujer y para la Igualdad de } & Oportunidades. & \\
\hline
\end{tabular}

Fuente: Instituto de la Mujer y para la Igualdad de Oportunidades. 
Si analizamos la situación desde un punto de vista temporal, sí que es cierto que el sesgo de género se ha reducido sensiblemente, si bien hay prestaciones en las que la mayor dependencia de las mujeres ha aumentado, como es el caso de las pensiones asistenciales y los subsidios de garantía de ingresos mínimos y de ayuda de terceras personas.

Tras repasar las tres generaciones de derechos, se contempla el concepto de ciudadanía como:

Un estatus que se concede a los miembros de pleno derecho de una comunidad. Sus beneficiarios son iguales en cuanto a los derechos y obligaciones que implica. Aunque no existe un principio universal que determine cuáles son los derechos y obligaciones, las sociedades donde la ciudadanía es una institución en desarrollo crean la imagen de una ciudadanía ideal que sirve para calcular el éxito y es objeto de las aspiraciones. (Marshall, 1950, p. 37).

Este concepto universal de ciudadanía acuñado por Marshall con el paso de los años ha suscitado críticas sensibles al género. De esta manera, Bottomore (1998) señala que los derechos sociales han sido reconocidos a las mujeres más lentamente que a los hombres. Las mujeres llegaron mucho más tarde a su reconocimiento y en el terreno concreto de los derechos sociales se les ha discriminado directamente a partir de no desarrollar servicios que les beneficiasen directamente: «guarderías diurnas, permisos por maternidad y planificación familiar» (Bottomore, 1998, p. 104). Las mujeres no ostentan los derechos de ciudadanía, y en el ámbito doméstico, soportan la responsabilidad de las actividades principales casi de forma íntegra. Esta afirmación es generalizada con independencia de las diferentes ideologías de los gobiernos que implementan las políticas sociales en Occidente. El autor advierte la necesidad de que las políticas sociales, junto con la presión de los movimientos sociales, deben ocuparse del reconocimiento de esta tercera generación de derechos, así como de acabar con los estereotipos de género que obstaculizan la igualdad y libertad de las mujeres en la esfera tanto pública como privada.

En este mismo hilo de críticas Teresa Montagut (1996) o Helga M. - Hernes (2003) consideran que parte de esta falta de reconocimiento viene dada por la ausencia de mujeres dentro de la clase política. Estas autoras sugieren que las mujeres no están lo suficientemente representadas en los diferentes órganos de gobierno y este hecho les perjudica, ya que no pueden ejercer la influencia necesaria que tenga en cuenta sus intereses. Carrasco (1997) o Martínez Herrero (2007), indican que los derechos que describe y categoriza Marshall (1950) están orientados a un individuo masculino, trabajador industrial, cabeza de familia nuclear heterosexual y occidental. Aclaran, al igual que Bottomore (1998), que las mujeres son beneficiarias de los derechos sociales de manera más precaria que los hombres. De hecho, Carrasco (1997) asegura encontrar tres tipos distintos de ciudadanía en los países europeos. 
Un primer grupo compuesto por clientes de asistencia social que estaría integrado mayoritariamente por mujeres. Un segundo grupo predominantemente masculino, donde los derechos sociales se adquirirían subsidiariamente de la participación en el mercado laboral. Y un tercer grupo, donde se encuentran aquellas personas que reciben los derechos de ciudadanía de forma subsidiaria, es decir, "cuyo acceso a los beneficios es indirecto, depende de las contribuciones dinerarias que haya realizado algún otro miembro de la familia que pertenezca a la fuerza de trabajo» (Carrasco, 1997, p. 34).

\subsection{Desmercantilización y empleo femenino}

Diferentes autoras consideran que el término desmercantilización está basado en un modelo de trabajador activo masculino. Tal y como determinan Carrasco (1997) o Montagut (1996), son los hombres los que se encuentran en mayor número representados como población activa y gran parte de su identidad como individuos se encuentra asociada a su integración laboral «el Estado del Bienestar está constituido siguiendo el estilo de vida masculino: durante la mayor parte de su vida, el hombre se relaciona con el mercado y cuando no puede, recibe un salario sustituto por parte del Estado» (Montagut, 1996, p. 412). Como se puede comprobar en el apartado anterior, este argumento tiene su traducción en las estadísticas proporcionadas por la Encuesta de Población Activa, que esbozan, en líneas generales, un mercado de trabajo con una mayor participación y oportunidades para los hombres.

A estos argumentos se añade la defensa de que la mercantilización de las mujeres aumenta sus derechos dentro de la familia. Habitualmente, la condición de asalariado/a facilita la independencia económica y la integración social de las personas. Por lo tanto, la mercantilización femenina dota de un mayor grado de autonomía a las mujeres, puesto que disminuye su posible dependencia económica. En este sentido, en el apartado anterior (Tabla 6) se comprueba la sobrerrepresentación de mujeres perceptoras de prestaciones no contributivas. Pero también se observan patrones dentro de las mujeres trabajadoras que deciden interrumpir sus trayectorias laborales por el cuidado de hijos e hijas o familiares dependientes. De esta forma, los datos del Ministerio de Empleo y Seguridad Social muestran que, durante el 2016, del total de excedencias por el cuidado de familiares, el $84,04 \%$ fue realizado por mujeres. En el caso de las excedencias por cuidado de hijos/as, este porcentaje asciende al 92,63\%. Las autoras referenciadas aseveran como error vincular mercado a mercantilización y Estado a desmercantilización. Una de las razones por las que los expertos y expertas catalogan los Estados del Bienestar de los países nórdicos como los mejores del mundo, es el porcentaje de mujeres dentro del mercado laboral. En estos casos, es el Estado, a través del empleo público, el principal promotor de la activación laboral de las mujeres, ejerciendo un papel mercantilizador. 
A partir de estos discursos (Montagut, 1996), se puede afirmar que el concepto de desmercantilización lleva implícito el sesgo de género que atenta contra los principios de solidaridad de los Estados del Bienestar sustentados en valores de igualdad de derechos de hombres y mujeres, autonomía o protección respecto al mercado.

\section{EL ESTADO DEL BIENESTAR BAJO UN ENFOQUE FEMINISTA}

Una vez esbozada la genealogía del Estado del Bienestar y revisada la aportación de las críticas feministas, en este epígrafe se presentan las propuestas de distintas autoras que centran su análisis en el género en relación con la provisión de bienestar, poniendo de relieve los principales conceptos que se introducen bajo una mirada de género.

\subsection{Políticas dirigidas a mujeres versus políticas de igualdad de género}

Una tónica que se sucede a la hora de interpretar la promoción de políticas sociales de género es la llegada de mujeres a las esferas de decisión. Hernes (2003) define esta presencia en las instituciones como fundamental, la aparición de mujeres en política marcará un antes y un después a la hora de tratar las políticas públicas atendiendo a las condiciones específicas de las mujeres.

El contenido y el tono del debate político sobre el género (...) es una curiosa mezcla de confirmación y desafío de ideales políticos, tales como igualdad y solidaridad: confirmación en la medida en que las feministas y las mujeres en general usan en forma consciente y positiva estos términos, proclamando su conveniencia, y estableciendo un desafío en la medida en que la tendencia masculina, en su contenido político y simbólico es criticada. (Hernes, 2003, p. 22).

Hernes (2003), además de reclamar el aumento de la representación política femenina, realiza una importante distinción dentro de las políticas públicas entre aquellas que hasta ahora concernían la vida de las mujeres y las que promueven la igualdad entre géneros. En las primeras, las mujeres son objetos y no sujetos. Se caracterizan por ser políticas íntimamente relacionadas con la familia y en las que se entiende al colectivo femenino en relación: madres, esposas e hijas, emplazadas preferentemente en el ámbito doméstico. Las mujeres no participan en la ejecución de las políticas, reciben la implementación como objetos de ellas. Sin embargo, en las políticas de igualdad entre los géneros se convierten en sujetos del proceso político «la política de igualdad de género se convierte en una política que se relaciona con el acceso de la mujer a los sectores de decisión y ejecución y también, 
como grupo, con el acceso al mercado de trabajo y al sistema educativo» (Hernes, 2003, p. 36).

Carrasco (1997) atiende a estas distinciones cuando analiza las políticas sociales españolas, advirtiendo que mantienen un claro sesgo al no considerar a las mujeres y a los hombres en situación de igualdad. La autora considera que se beneficia a los trabajadores a tiempo completo, lo que crea una precarización de la protección para aquellos/as que no participan de igual manera en el mercado laboral, perjudicando seriamente a multitud de mujeres. La clave que puede eliminar este sesgo de las políticas sociales es redefinir el concepto de trabajo, visibilizando el trabajo reproductivo que realizan principalmente las mujeres y, por tanto, otorgando valor al bienestar social que producen y ofreciendo una protección social que se adecue a esta aportación.

\subsection{La mercantilización libertadora}

Si tenemos en cuenta los datos presentados en el tercer epígrafe de este trabajo, se deduce la necesidad de establecer estudios que tengan en cuenta en qué medida muchas mujeres tienen una situación inestable dentro del mercado laboral y le otorgan a su mercantilización un carácter secundario, es decir, sus rendimientos de trabajo aparecen como una aportación económica extra a la economía familiar, circunstancia que limita su autonomía económica y, por ende, promociona la dependencia y la pérdida de estatus y poder dentro de la unidad convivencial. Mientras tanto, continúan responsabilizándose del trabajo reproductivo independientemente de su total o parcial mercantilización. A este respecto, Orloff (1993) destaca las dimensiones acceso al empleo y autonomía. La autora recapacita en torno a la relación existente entre el acceso de las mujeres al empleo remunerado y su autonomía dentro del ámbito familiar. Así, el salario percibido puede potenciar la autonomía de las mujeres dentro de la unidad familiar e incluso tener la capacidad suficiente para crear un hogar independientemente de tener o no pareja estable.

\subsection{Dependencia/Independencia intrafamiliar}

Atendiendo a los aspectos de dependencia e independencia de las mujeres, y amparándonos en los discursos de Ruth Lister (1990), podemos defender la idea de que, para lograr la interdependencia entre los miembros de una unidad convivencial, es necesario reducir a la mínima expresión la dependencia económica involuntaria de sus miembros. Para lograr esta finalidad resulta de obligado cumplimiento conocer cuáles son las pautas de conducta existentes entre los miembros de una unidad convivencial en relación al trabajo productivo y reproductivo. De esta forma, podemos interpretar estas relaciones de las personas analizando la forma en que satisfacen sus necesidades sociales a partir de los principales provisores de bienestar. 


\subsection{Trabajo remunerado y no remunerado en relación con el bienestar. Nueva tipología del Estado del Bienestar}

Estudiar el trabajo remunerado y no remunerado en relación con el bienestar implica aproximarnos a conocer las contribuciones teóricas de Jane Lewis (1992), ya que esta autora:

no ha intentado incorporar la variable género a los modelos dominantes sino más bien ha denunciado el carácter incompleto de dichas comparaciones creando para ello un nuevo marco analítico basado en las relaciones de género y su institucionalización en los sistemas de protección social. (Martínez Herrero, 2007, p. 105).

Lewis (1994) distingue cuatro aspectos diferentes a la hora de tener en cuenta la categoría género, todos ellos relacionados con los antecedentes históricos del Estado del Bienestar. Un primer aspecto sería aquel en el que se concibe a las mujeres como perceptoras de ayudas sociales en relación a la familia, dentro de su condición de madres y/o esposas. En un segundo término, aparece la separación de esferas pública y privada del que se nutre el modelo. El tercero está relacionado con la división sexual del trabajo, en la que el llamado cabeza de familia varón mantiene a los miembros de la unidad convivencial, mientras que las mujeres se encargan del trabajo reproductivo. El cuarto aspecto está definido por la protección social que continúa desarrollándose bajo principios contributivos, lo que genera que exista un sistema dual donde el género mantiene un protagonismo importante. Los hombres se mantienen como principales usuarios de las prestaciones y ayudas dependientes de la seguridad social y las mujeres de las prestaciones gestionadas por los servicios sociales/asistencia social, con la diferencia cualitativa y cuantitativa que ello conlleva.

- De acuerdo con estos cuatro aspectos, Lewis (1994) analiza los Estados del Bienestar de cuatro países europeos (Reino Unido, Irlanda, Francia y Suecia) y diferencia tres modelos:

- Modelo fuerte: Caracterizado por la separación de esferas público/privada, en este modelo las mujeres presentan una baja tasa de mercantilización con un mayor grado de temporalidad y precariedad. Además, independientemente de acceder o no al mercado laboral, continúan responsabilizándose del trabajo de cuidados. Los derechos sociales se ostentan con desigualdad porque las mujeres los disfrutan de manera subsidiaria al sustentador principal, mientras que los hombres lo hacen a partir de sus rendimientos de trabajo. Los países que mejor representan esta categoría son Irlanda y Gran Bretaña.

- Modelo moderado: Las mujeres tienen una mayor inserción laboral, con contratos a tiempo completo, por lo que disfrutan de los derechos sociales 
a partir de sus contribuciones a la seguridad social. La maternidad es entendida como función social y no como asunto privado, lo que da lugar a la promoción de políticas de prestaciones que trae como consecuencia que las familias que tienen descendencia obtengan mayores beneficios. La autora incluye a Francia en esta caracterización.

- Modelo débil: Concibe a hombres y mujeres como individuos susceptibles de ser mercantilizados, trata a las mujeres como trabajadoras, pero también como máximas responsables del trabajo reproductivo, por lo que se generan políticas destinadas a ellas para la promoción de la conciliación del trabajo productivo y no reproductivo. Aunque las mujeres reciben ciertas «facilidades» para poder responsabilizarse de ambos trabajos, las políticas implementadas no eliminan el hecho de que los hombres permanezcan alejados de la corresponsabilidad. Esta lógica perpetúa las desigualdades de género dentro de los hogares. El país que mejor identifica el modelo débil es Suecia.

\subsection{El modelo male breadwinner versus el modelo individual}

Diane Sainsbury (1994) desarrolla aún más los estudios de Lewis (1994), centrándose en la unidad de referencia en que se basan los sistemas de protección social de países como Estados Unidos, Reino Unido, Suecia y Países Bajos. Su propuesta consiste en presentar las desigualdades existentes entre un modelo de Estado del Bienestar cuyas ayudas, servicios y prestaciones están orientados a una unidad de referencia familiar frente a otro centrado en las personas de manera individualizada. Dependiendo de la presencia o ausencia de familiarismo' nos encontramos con dos modelos diferenciados: el modelo male breadwinner, definido por Lewis (1994) y que conocemos en castellano como varón sustentador u hombre ganador de pan; y el modelo individual.

El modelo male breadwinner se caracteriza por la división sexual del trabajo, que mantiene los roles tradicionales en los que los hombres están encargados de proveer a la familia ${ }^{10}$ de bienes a partir de su mercantilización, y las mujeres reciben la responsabilidad de encargarse de los cuidados y labores del hogar en la esfera doméstica. El sistema de prestaciones, cotizaciones y derechos sociales giran en torno a este modelo y son de carácter contributivo, de manera que, habitualmente, los que aportan bienestar material a la unidad familiar con sus salarios se convierten en los beneficiarios titulares de las ayudas y prestaciones que recibe la unidad familiar (generalmente hombres). Las mujeres, los niños y niñas, y las personas

10 Familias que se conciben bajo una ideología conservadora preferentemente como nucleares y heterosexuales. 
dependientes de la unidad familiar son beneficiarios/as de estos recursos en tanto en cuanto lo sea el varón sustentador. Como señala Martínez Herrero (2007, p. 111) «la familia o el hogar es la unidad de cotización de los seguros sociales y de los impuestos fiscales; y además se beneficia a la familia con unas deducciones fiscales como forma de compensarla por el mantenimiento de sus miembros». Francia y Alemania se encuentran en esta categoría.

El modelo individualista no va a diferenciar entre hombres y mujeres a la hora de desarrollar su sistema de cotizaciones, impuestos fiscales o seguros sociales. Se entiende que cada uno de los miembros responsables de la unidad convivencial debe asumir el trabajo reproductivo y el productivo. El mercado de trabajo, en principio, no favorece a ningún género. Las esferas pública y privada no están tan delimitadas como en el anterior modelo debido a que poseen un sistema de servicios y prestaciones muy amplio de atención a las dependencias. Se entiende el ejercicio reproductivo como una función social, un principio que repercute positivamente en las personas que lo ejercen, ya que se les gratifica a partir de seguros sociales con independencia de que desarrollen o no esta función dentro de sus hogares. Suecia podría entenderse como representante de este modelo.

\subsection{Los cuidados o social care. La introducción de la función de cuidados en las tipologías de Estados del Bienestar}

Son muchas las teóricas ${ }^{11}$ que han situado los cuidados como elemento central de análisis cuando analizamos la provisión de bienestar.

Jane Jenson $(1997,2002)$ propone un sistema de clasificación de los sistemas de protección social a partir de las respuestas en materia de cuidados en base a tres cuestiones fundamentales. La primera está relacionada con la responsabilidad del cuidado, de manera que podemos diferenciar los sistemas de provisión de bienestar donde los cuidados recaen sobre agentes públicos, de aquellos en los que recaen sobre la unidad convivencial, con ayuda institucional o sin ella. Además, dentro de la familia también podemos distinguir entre la responsabilidad de los cuidados en exclusiva por parte de las mujeres o a partir de la existencia de corresponsabilidad en el hogar. La segunda cuestión afecta a la financiación de esta ocupación, es decir, los costes del cuidado son asimilados por la familia, por el Estado o por el empleador o empleadora. Y la última cuestión gira en torno al suministro de los cuidados, con ella se pretende conocer si los cuidados son proporcionados por el sector público, por el mercado o por el tercer sector.

Las respuestas a las cuestiones que la autora plantea nos ofrecen diferentes modelos de provisión social, lo que nos ayuda a tener presente la importancia de

11 Lewis (2011); Daly y Lewis (2011); Carrasco (1997, 2004); Carrasco, Borderías y Torns (2011); Benería (2011); Jenson (1997); Comas d’Argemir (2000); Montagut (1996, 2000). 
analizar la desigualdad de funciones y poder existente entre hombres y mujeres dentro de las unidades convivenciales. Jenson (1997) nos exhorta a descubrir cómo las políticas públicas de cada país promocionan o minimizan dichas desigualdades.

Paralelamente a los estudios de Jenson, los análisis de Mary Daly y Jane Lewis (2011) se proponen examinar el concepto de social care desde una línea más actual y en relación a los cuidados:

con el propósito de clarificar y desarrollar su potencial analítico en relación con el estudio de los Estados del Bienestar y cómo éstos están cambiando. Por consiguiente, centramos la atención en el modo en que los cuidados se sitúan en la intersección público/privado (...) lo formal y lo informal; lo remunerado y lo no remunerado; y las prestaciones en forma monetaria y en forma de servicios. (Daly y Lewis, 2011, p. 226).

Daly y Lewis (2011) efectúan su exposición a partir de tres afirmaciones fundamentales. La primera defiende la importancia analítica del concepto de cuidados. Una categoría que las autoras manifiestan necesaria a la hora de comprender la forma y naturaleza de los Estados del Bienestar contemporáneos. La ambigüedad del concepto de cuidados le ha hecho ser susceptible de discusiones y cambios. En un principio se limitaba a una de las actividades que realizaban las mujeres en el ámbito doméstico, pero después se han desarrollado teorías en torno a la complejidad de estas funciones en las que también intervienen las emociones, así como las relaciones interpersonales. Más tarde, el debate se incorpora paulatinamente al ámbito público entrando en la agenda de las políticas sociales.

Todo este recorrido y la diversidad de definiciones alrededor de los cuidados obliga a Daly y Lewis (2011) a ofrecernos un concepto que abarque todas las dimensiones que hemos referido: la primera, entender los cuidados como trabajo, la segunda dimensión como marco normativo de obligación y responsabilidad y la tercera como actividad que implica costes (económicos y emocionales). Abordando estas tres dimensiones conciben los cuidados o social care como «el conjunto de las actividades y las relaciones que intervienen en la satisfacción de las necesidades físicas y emocionales de las personas adultas dependientes y de las niñas y niños, y los marcos normativos, económicos y sociales en los que aquellas se asignan y se desarrollan» (Daly y Lewis, 2011, p. 231).

La segunda afirmación que plantean Daly y Lewis (2011) al examinar el concepto de social care dentro del análisis de los Estados del Bienestar está relacionada con la necesidad de situar el social care en el centro de los estudios que traten las tipologías de provisión social porque su centralización puede producir variaciones. En este apartado tratan los cambios acaecidos en los últimos tiempos que problematizan la cuestión de los cuidados, así como la intervención de las instituciones públicas: 
mientras que la demanda de cuidados se va incrementando, las responsabilidades familiares tradicionales (donde encontramos el papel de las mujeres y su mercantilización) están decreciendo. Estas dificultades que experimentan las sociedades europeas comienza a denominarse crisis de los cuidados.

Esta crisis no podemos abordarla de manera homogénea, porque cada país ha asumido las responsabilidades del social care de modo diverso. Aun así, las autoras diferencian tres bloques principales. El primer bloque está compuesto por los países escandinavos, que se definen por colectivizar el cuidado de personas mayores, niñas y niños y por mantener (aunque no como en el pasado) un sistema de servicios sociales universales financiados por vía impositiva. Las presiones a las que se ven sometidos tienen su origen en la escasez de fondos públicos para atender esta actividad. El segundo bloque lo integran los países del centro y del sur del continente, son países que parecen orientados a privatizar los cuidados, pero con diferentes enfoques. De un lado, los países mediterráneos tienden a privatizar los cuidados por medio de la responsabilidad familiar. Italia se desmarca con servicios limitados de atención a las dependencias (personas mayores, niñas y niños) y escasa participación del mercado en actividades relacionadas con el cuidado. En Alemania se privatizan los cuidados a favor de las familias, y las atenciones extrafamiliares las asume el sector del voluntariado. Francia, sin embargo, diferencia entre receptores de cuidados, manteniendo solo la responsabilidad pública sobre menores. Todos los países que se encuentran en este bloque (países mediterráneos, Alemania y Francia) se ven presionados por la escasez de oferta de cuidados. El último bloque lo comprenden los países que poseen un Estado del Bienestar de corte beveridgeriano (Reino Unido e Irlanda). Estos países, al igual que Francia, también diferencian entre los receptores de cuidados, pero, justo al contrario que el país galo, no intervienen en la atención a los menores, siendo más probable que asuman la responsabilidad de cuidados sobre las personas mayores.

Daly y Lewis (2011) también advierten las variaciones que los diferentes Estados y sus políticas sociales han ido incorporando en esta materia, ya que anteriormente no se concebía la noción de dependencia como sí se piensa en estos momentos. Además, en los países europeos dentro del modelo central/meridional, es imprescindible destacar la solidaridad familiar que tradicionalmente les define y que supone que las políticas sociales se diseñen de acuerdo al principio de permitir a las familias ejercer su derecho a cuidar.

La tercera y última afirmación que subrayamos de Daly y Lewis (2011) está referida a la reestructuración del propio modelo de provisión social en relación a la actividad del cuidado. Las autoras subrayan que, en la actualidad, son numerosos los cambios económicos, sociales, políticos y culturales que se están produciendo en los países y que afectan: a la naturaleza de los cuidados, al planteamiento de su responsabilidad, a los costes que suponen, a la intervención más adecuada, etc. Daly 
y Lewis (2011) acentúan el mayor protagonismo que está adquiriendo el mercado en la provisión de los cuidados. También sostienen la necesidad de investigar los cambios que se están produciendo en cuanto a la combinación entre prestaciones económicas y servicios de atención al cuidado

En último término y relacionado con esta tercera afirmación, Daly y Lewis (2011) tratan los cambios que se están produciendo con respecto a la naturaleza de los derechos sociales desde el punto de vista de la provisión de servicios. Ambas entienden que la progresiva mercantilización de los cuidados genera que los recursos sociales se destinen a la población más necesitada, tendencia que se traduce en una «mayor influencia de la discrecionalidad profesional en la determinación de quién recibirá dichos servicios» (Daly y Lewis, 2011, p. 245). Las personas con una menor dependencia o que puedan disponer de personal cuidador quedarán fuera de la provisión, dificultándose el carácter universal de los servicios sociales tal y como aparecen programados.

\section{CONSIDERACIONES FINALES: ¿HABLAMOS DE EXPROPIACIÓN DEL BIENESTAR?}

Las desigualdades sociales forman parte de nuestra realidad cotidiana. Como advierte Melucci (2001), estas desigualdades están creadas a partir de una escasa o nula distribución de recursos económicos, culturales y sociales, que dualizan el mundo en personas poseedoras y personas desposeídas.

Las mujeres, históricamente, no han poseído un estatus de ciudadanía en igualdad de condiciones respecto a los hombres. La genealogía presentada en este trabajo así lo demuestra. Los derechos civiles, políticos y sociales han sido una lucha continua y permanente de parte de la población; los ideales ilustrados se conforman para una élite y, paulatinamente, la población, a partir de la movilización y la lucha, van conquistando la posibilidad de acceder a ellos. No obstante, podemos concluir que las mujeres no han logrado un nivel de ciudadanía plena en ninguna de las generaciones de derechos analizados.

Simultáneamente a la conformación de los Estados modernos, se internalizan paulatinamente elementos de protección a la población, función que en anteriores siglos había sido ejercida casi en exclusiva por la Iglesia. Familia, Estado y Mercado se manifiestan como los principales proveedores de bienestar social para las personas en las sociedades occidentales. Pero, evidentemente, estos tres elementos proveedores tienen naturalezas y fórmulas de provisión muy diferentes.

Los países mediterráneos basan su fuente principal de provisión en las familias. Sin embargo, el Estado del Bienestar español está inserto en los sistemas de protección social denominados familiaristas, es decir, teóricamente basados en la provisión de bienestar de las familias. No obstante, la mayoría de estudios subrayan 
que es la provisión que realizan fundamentalmente las mujeres a través del ejercicio de cuidados, a partir de su trabajo reproductivo, la que verdaderamente supone el soporte principal del Estado del Bienestar. La lógica de la división sexual del trabajo impera en los sistemas de protección social europeos, haciéndose más profunda en los países mediterráneos que han desarrollado estos modelos con un carácter más tardío.

Las consecuencias de esta ausencia de protección social «equivalente» entre hombres y mujeres se manifiesta en la tardía incorporación masiva de las mujeres al mercado laboral, en comparación con el resto de europeas. Peores tasas de actividad, ocupación y desempleo dan cuenta de estas circunstancias. Aun así, se puede afirmar que estamos asistiendo a un momento histórico. Las mujeres han accedido a la mercantilización y han alcanzado unas tasas de participación que nunca antes en la historia moderna de Europa se había producido. A pesar de ello, las condiciones laborales, en comparación con la otra mitad de la ciudadanía, merece una reflexión, ya que los Estados del Bienestar continúan siendo subsidiarios del mercado laboral, lo que supone que las personas que no mantienen trayectorias laborales estables no consiguen acceder a prestaciones adecuadas para satisfacer sus necesidades básicas. Además, es preciso remarcar la importancia del trabajo reproductivo, que no tiene un reconocimiento suficientemente materializado en prestaciones por parte del Estado, y supone una función básica para el mantenimiento de la sociedad.

Las teorías críticas feministas referenciadas en este trabajo ponen en tela de juicio todos estos elementos discriminantes. Estas teorías cuestionan las condiciones en que se controla y consume la provisión de bienestar que el trabajo reproductivo reporta a la población en su conjunto, puesto que, a cambio, ofrece a sus proveedoras una protección exigua e insuficiente que les condena a la dependencia de los miembros de sus unidades convivenciales que sí hayan mantenido trayectorias laborales estables.

En definitiva, volviendo a Melucci (2001), las personas mercantilizadas poseen protección social gracias a que otras personas que carecen de esta protección (fundamentalmente mujeres) han colaborado para sustentar un sistema de ayudas, servicios y prestaciones de las que luego se les desposee, efectuándose, por ello, un ejercicio de expropiación del bienestar. Expropiación que les impide integrarse en el mercado laboral en condiciones igualitarias, expropiación que les genera malestar y falta de cobertura social. Obstáculos, todos ellos, que les imposibilitan disfrutar de los derechos sociales en igualdad de condiciones. Pero, como prosigue el sociólogo y psicólogo clínico «el problema de los "otros" [en este caso, las mujeres] pesa sobre nosotros, los privilegiados, porque este mundo continuará existiendo sólo si estos "otros" forman parte de él. De lo contrario se deslizará, paulatina o súbitamente, hacia la catástrofe» (Melucci, 2001, p. 54). 


\section{REFERENCIAS BIBLIOGRÁFICAS}

Aguirre, D., Hoteit, L., Rupp, C., Sabbagh, K. (2012). Empowering the Third Billion. Women and the World of Work in 2012. PWC Report. Recuperado el 12 de junio de 2017, de https://www.strategyand.pwc.com/media/file/Empowering-thethird-billion_Briefing-report.pdf

Alemán Bracho, C., Alonso Seco, J. M., Fernández Santiago, P. (2010). Fundamentos de Servicios Sociales. Valencia: Tirant lo Blanc.

Alemán Bracho, C., Trinidad Requena, A. (2006). Servicios Sociales: planificación y evaluación. Navarra: Aranzadi.

Alonso, L. E. (1999). Trabajo y ciudadanía: Estudios sobre la crisis de la sociedad salarial. Madrid: Trotta.

Amorós, C., Cobo, R. (2007). Feminismo e llustración. En C. Amorós, A. De Miguel (eds.), Teoría feminista: de la Ilustración a la globalización. De la llustración al segundo sexo (pp. 91-144). Madrid: Minerva Ediciones.

Amorós, C., De Miguel, A. (2007). Introducción: Teoría feminista y movimientos feministas. En C. Amorós, A. De Miguel (eds.), Teoría feminista: de la llustración a la globalización. De la llustración al segundo sexo (pp. 13-90). Madrid: Minerva Ediciones.

Arrazola García, L. (1832). Enciclopedia española de derechos y administración o Nuevo Teatro Universal de la Legislación de España e Indias. Madrid: Imprenta de Díaz y Compañía.

Artola Gallego, M., Pérez Ledesma, M. (1990). Historia del mundo contemporáneo. Madrid: Anaya.

Benería, L. (2011). Crisis de los cuidados, migración internacional y políticas públicas. En C. Carrasco, C. Borderías, T. Torns (eds.), El trabajo de cuidados: historia, teoría y políticas (pp. 359-389). Madrid: Catarata.

Beveridge, W. H. (1989). Seguro social y servicios afines. Informe de Lord Beveridge. Madrid: Ministerio de Trabajo y Seguridad Social. 
Bottomore, T. (1998). Ciudadanía y clase social, cuarenta años después. En T. H. Marshall, T. Bottomore (coord.), Ciudadanía y clase social (pp. 83-142). Madrid: Alianza.

Caine, B., Sluga, G. (2000). Género e Historia: mujeres en el cambio sociocultural europeo, de 1780 a 1920. Madrid: Narcea.

Carrasco, C. (1997). Mujeres y Estado del Bienestar: Un debate teórico. En C. Carrasco, A. Alabart, M. Mayordomo, T. Montagut (coord.), Mujeres, trabajos y políticas sociales: una aproximación al caso español (pp. 17-48). Madrid: Instituto de la Mujer.

Carrasco, C. (2004). El cuidado: ¿coste o prioridad social? En A. Rincón (coord.), Congreso Internacional Sare 2003: "Cuidar cuesta: costes y beneficios del cuidado» (pp. 31-37). Vitoria-Gasteiz: Emakunde.

Carrasco, C., Borderías, C. Torns, T. (2011). El trabajo de cuidados: historia, teoría y políticas. Madrid: Catarata.

Cobo, R. (1995). Fundamentos del patriarcado moderno. Jean Jacques Rousseau. Madrid: Cátedra.

Comas d’Argemir, D. (2000). Mujeres, familia y Estado del Bienestar. En M. T. del Valle Murga (coord.), Perspectivas feministas desde la antropología social (pp. 187-204). Barcelona: Ariel Antropología.

Cuberes, D., Teignier, M. (2014). Gender inequality and economic growth: A critical review. Journal of International Development, 26, 260-276.

Daly, M., Lewis, J. (2011). El concepto de social care y el análisis de los Estados del Bienestar contemporáneos. En C. Carrasco, C. Borderías, T. Torns (Eds.), El trabajo de cuidados: historia, teoría y políticas (pp. 225-251). Madrid: Catarata.

Del Pino, E. y Rubio Lara, M. J. (2016). Los Estados de Bienestar en la encrucijada. Políticas sociales en perspectiva comparada. Madrid: Tecnos.

Dollar, D., Gatti, R. (1999). Gender inequality, income and growth: are good times good for women? Policy Research Report on Gender and Development Working Paper Series No. 1. Washington, DC: World Bank. 
Duhet, P. M. (1989). 1789-1793: La voz de las mujeres en la revolución francesa. Barcelona: La Sal.

Elborgh-Woytek, K., Newiak, M., Kochhar, K., Fabrizio, S., Kpodar, K., Wingender, P., Clements, B., Schwartz, G. (2013). Women, Work and the Economy: Macroeconomic gains from gender equity. IMF Staff Discussion Note, $\mathrm{SND} / 12 / 10$.

Esping-Andersen, G. (1990). Los tres mundos del Estado del Bienestar. Valencia: Edicions Alfons El Magnanim.

Esping-Andersen, G. (2000). Fundamentos sociales de las economías postindustriales. Barcelona: Ariel.

Esping-Andersen, G. (2008). Modelos de Sociedad, Economía y Políticas Públicas: un nuevo contrato de género. Madrid: Instituto de Estudios Fiscales.

Fernández Cordón, J.A., Tobío Soler, C. (2005). Conciliar las responsabilidades familiares y laborales: políticas y prácticas sociales. Madrid: Fundación Alternativas.

Gallego Ayllón, M. J., González Vélez, M. (1997). Aproximación a la Acción Social y a los Servicios Sociales. Huelva: Cuché.

Giddens, A. (2009). Sociología. Madrid: Alianza Editorial.

Hernes, H. M. (2003). El poder de las mujeres y el Estado del Bienestar. Madrid: Vindicación Feminista.

Jenson, J. (1997). Who cares? Gender and Welfare Regimes. Social Politics, 4, 182187.

Keynes, J. M. (2006). Teoría general del interés, la ocupación y el dinero. Madrid: Fondo de Cultura Económica.

Leibfried, S. (1993). Towards an European welfare state? On integrating poverty regimes in the European Community. En C. Jones (ed.), New perspectives on the welfare state in Europe. London: Routledge.

Lewis, J. (1994). Género y estudio de los sistemas de asistencia. Revista Arenal, 1, 49-68. 
Lewis, J. (2011). Género, envejecimiento y el nuevo pacto social: la importancia de desarrollar un enfoque holístico de las políticas de cuidados. En C. Carrasco, C. Borderías, T. Torns (eds.), El trabajo de cuidados: historia, teoría y políticas (pp. 336-358). Madrid: Catarata.

Lister, R. (1990). Women, Economic Dependency and Citizenship. Journal of Social Policy, 19(4), 445-467.

Marshall, T. H. (1950). Citizenship and social class. Cambridge: Cambridge University Press.

Martínez Herrero, M. J. (2007). Las políticas familiares en Europa: Una aproximación al Estado del Bienestar desde un enfoque de género. Bilbao: Dirección para la Igualdad de la Universidad del País Vasco/Euskal Herriko Unibersitatea.

Marx, K. (1864). Address and provisional rules of the working men's international association, established September 28, 1864. London.

Melucci, A. (2001). Vivencia y convivencia: teoría social para la era de la información. Madrid: Trotta.

Mishra, R. (1990). The welfare state in capitalist society: policies of retrenchment and maintenance in Europe, North America and Australia. New Jersey: PrenticeHall.

Molina Petit, C. (1994). Dialéctica Feminista de la Ilustración. Barcelona: Anthropos.

Montagut, M. (1996). La mujer en el Estado del Bienestar: un vacío teórico. En VV. AA. Dilemas del Estado del Bienestar (405-420). Madrid: Fundación Argentaria.

Montagut, M. (2000). Política social: Una introducción. Barcelona: Ariel.

Moreno, L. (1999). La «vía media» española del régimen de bienestar mediterráneo. Madrid: IESA-CSIC.

Moreno, L. (2000). Ciudadanos precarios: la última red de protección social. Barcelona: Ariel.

Moreno, L. (2003). Bienestar mediterráneo y «supermujeres». Revista Española de Sociología, 2, 41-56. 
Moreno, L. y Marí-Klose, P. (2016). Bienestar Mediterráneo: trayectorias y retos de un régimen en transición. En E. Del Pino y M. J. Rubio Lara (dirs.), Los Estados de Bienestar en la encrucijada. Políticas sociales en perspectiva comparada (pp. 126-146). Madrid: Tecnos.

Nash, M. (1993). Identidad cultural y género, discurso de la domesticidad y la definición del trabajo de las mujeres en la España del siglo XIX. En G. Duby, M. Perrot (eds.), Historia de las mujeres (pp. 585-598). Madrid: Taurus.

OECD. (2014). Achieving stronger growth by promoting a more gender-balanced economy. Report prepared for the G20 Labour and Employment Ministerial Meeting. Melbourne, Australia, 10-11 September 2014. Recuperado el 8 de junio de 2017, de https://www.oecd.org/g20/topics/employment-and-socialpolicy/ILO-IMF-OECD-WBG-Achieving-stronger-growth-by-promoting-a-moregender-balanced-economy-G20.pdf

Orloff, A. S. (1993). Gender and the social rights of citizenship: the comparative analysis of gender relations and welfare states. American Sociological Review, 58(3), 303-328.

Palier, B. (2016). El régimen de bienestar continental: De un sistema congelado a las reformas estructurales. En E. Del Pino y M. J. Rubio Lara (dirs.), Los Estados de Bienestar en la encrucijada. Políticas sociales en perspectiva comparada (pp. 69-94). Madrid: Tecnos.

Polanyi, K. (1989). La gran transformación. Madrid: Ediciones de la Piqueta.

Puleo, A. H. (1993). La ilustración olvidada. La polémica de los sexos en el siglo XVIII. Barcelona: Anthropos.

Rodríguez Cabrero, G. (1997). Por un nuevo contrato social: el desarrollo de la reforma social en el ámbito de la Unión Europea. En L. Moreno (ed.), Unión Europea y Estado del Bienestar (pp. 3-30). Madrid: CSIC.

Rodríguez Cabrero, G. (2004). El Estado del Bienestar en España: debates, desarrollo y retos. Madrid: Fundamentos.

Sainsbury, D. (1994). Gendering Welfare States. London: Sage Publications. 
Sánchez Muñoz, C. (2001). Genealogía de la vindicación. En E. Beltrán, V. Maquieira (eds.), Feminismos, debates teóricos contemporáneos (pp. 17-74). Madrid: Alianza.

Scott, J. W. (1993). La mujer trabajadora en el siglo xIx. En G. Duby, M. Perrot (eds.), Historia de las mujeres (pp. 405-435). Madrid: Taurus.

Thiebaut, C. (ed.). (1991). La herencia ética de la Ilustración. Barcelona: Crítica.

Trifiletti, R. (1999). Southern European welfare regimes and the worsening position of women. Journal of European Social Policy, 9(1), 49-64.

Valcárcel, A. (1991). Sobre la herencia de la igualdad. En C. Thiebaut (ed.), La herencia ética de la Ilustración (pp. 153-175). Barcelona: Editorial Crítica.

Valcárcel, A. (2008). La política de las mujeres. Madrid: Cátedra. 
Página intencionadamente en blanco. 